\title{
WestVirginiaUniversity
}

THE RESEARCH REPOSITORY @ WVU

Graduate Theses, Dissertations, and Problem Reports

2016

\section{A Case of the Mundanes}

\author{
Nathan Ditzler
}

Follow this and additional works at: https://researchrepository.wvu.edu/etd

\section{Recommended Citation}

Ditzler, Nathan, "A Case of the Mundanes" (2016). Graduate Theses, Dissertations, and Problem Reports. 5500.

https://researchrepository.wvu.edu/etd/5500

This Thesis is protected by copyright and/or related rights. It has been brought to you by the The Research Repository @ WVU with permission from the rights-holder(s). You are free to use this Thesis in any way that is permitted by the copyright and related rights legislation that applies to your use. For other uses you must obtain permission from the rights-holder(s) directly, unless additional rights are indicated by a Creative Commons license in the record and/ or on the work itself. This Thesis has been accepted for inclusion in WVU Graduate Theses, Dissertations, and Problem Reports collection by an authorized administrator of The Research Repository @ WVU. For more information, please contact researchrepository@mail.wvu.edu. 


\title{
A Case of the Mundanes
}

\author{
Nate Ditzler
}

\author{
Thesis submitted \\ to the College of Creative Arts \\ at West Virginia University \\ in partial fulfillment of the requirements for the degree of \\ Master of Fine Arts in \\ Ceramics
}

Shoji Satake, committee chair, M.F.A.

Dylan Collins, M.F.A. Jason Lee, M.F.A.

Robert Moore, M.F.A.

Kristina Olson, M.A

Naijun Zhang, M.F.A.

School of Art and Design

Morgantown, West Virginia

2016

Keywords: Ceramics, Sculpture, Mixed Media, Biomorphic forms, The Everyday, Humor

Copyright 2016 Nate Ditzler 


\section{Abstract \\ A Case of the Mundanes}

Nate Ditzler

This written thesis is the supporting documentation for $A$ Case of the Mundanes, my Master of Fine Arts thesis exhibition. The exhibition seeks to give a visual presence to the seemingly trivial and overlooked moments of everyday life. It contains six individual sculptures made of handmade ceramic forms, fabricated mixed media elements, and modified found objects. The intention of $A$ Case of the Mundanes is to combine nuances of humor to bring lightheartedness to the foibles and anxieties found in everyday life. The exhibition combines familiar and surreal representations to explore the way in which an artwork's meaning can shift, as well as the way in which the viewer can enter into the work based on their own subjective reality. By employing these strategies, the work seeks to raise questions regarding the complexities and paradoxes found in the everyday. 


\section{Acknowledgements}

I would like to express my sincere gratitude to all of my committee members, professors, and fellow graduate students. I would also like to especially thank my partner Laura A. Konecne, for the support, conversations, assistance, and technical insights during my M.F.A. degree. Last but not least I would like to thank my parents for all of their support along the way. This exhibition concludes a three-year journey of self-guided discovery to find my visual language. I am truly thankful to everyone who played a role in my artistic development. 


\section{Table of Contents}

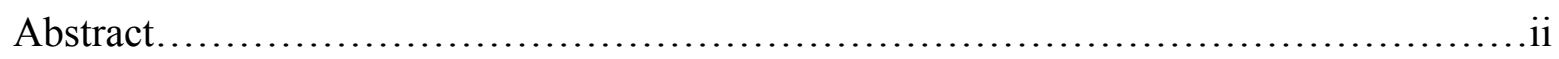

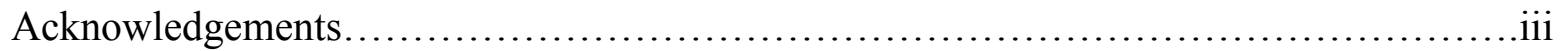

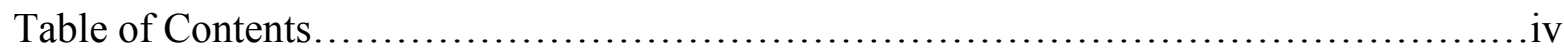

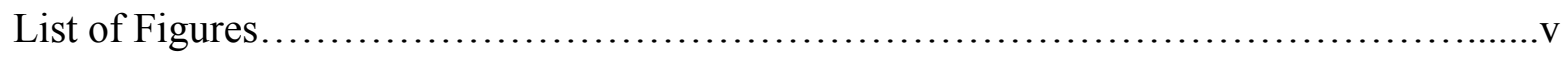

Introduction..................................................................

I. Conceptual Framework

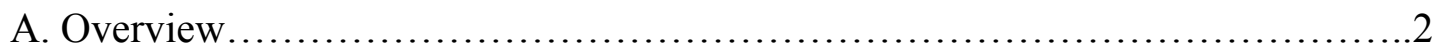

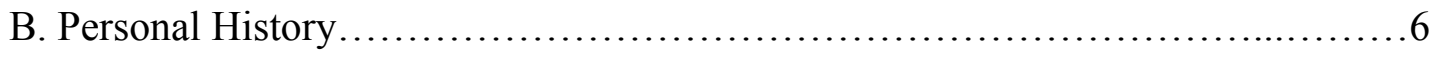

II. Contemporary Art Influences

A. Aesthetics of Accessing and Activating the Space............................

B. Words and Imagery ................................................ 10

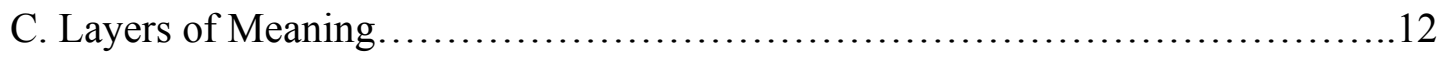

III. Analysis

A. Instigations and the Process of Making.................................... 15

B. Conclusion............................................................ 21

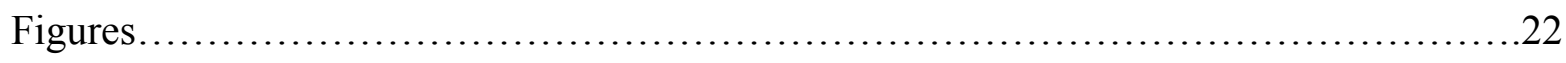

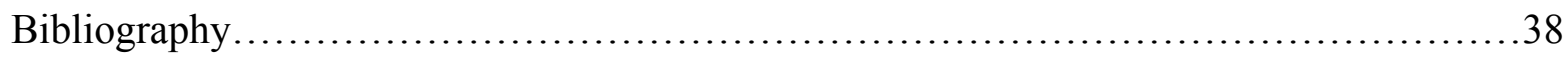

Resumé....................................................................40 


\section{List of Figures}

Figure 1. Nate Ditzler, A Case of the Mundanes (Wall vinyl)............................22

Figure 2. Nate Ditzler, A Case of the Mundanes (Installation view).......................22

Figure 3. Charles Schulz, Peanuts Comic, n.d.......................................23

Figure 4. Ernest H. Shepard, The Tao of Pooh, n.d...................................23

Figure 5. Trina Paulus, Hope for the Flowers, 1972..................................24

Figure 6. Nate Ditzler, Sweater Weather (image includes the artist).......................24

Figure 7. Nate Ditzler, Flight Risk ..............................................25

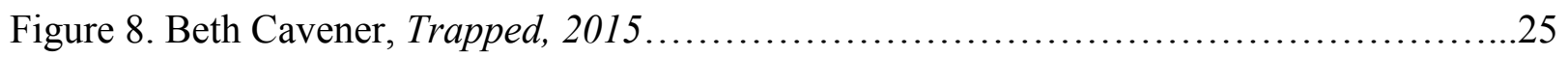

Figure 9. Nate Ditzler, Fun Without Friends............................................26

Figure 10. Nate Ditzler, The Big Picture (detail).......................................26

Figure 11. Martin Heidegger, Hermeneutic Cycle..........................................27

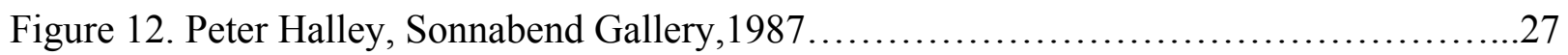

Figure 13. Robert Morris, Installation view of exhibition at the Green Gallery, 1964..........28

Figure 14. Nate Ditzler. Sweater Weather (Installation view)..............................28

Figure 15. Nate Ditzler, Flight Risk (detail)......................................29

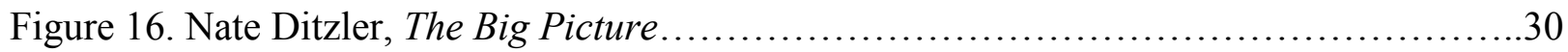

Figure 17. Nate Ditzler, Fun Without Friends (alternate view).................................

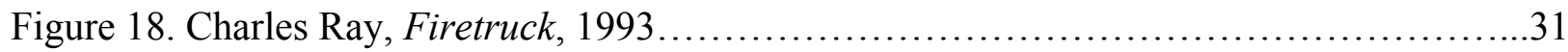

Figure 19. Nate Ditzler, All Work and No Play Makes Us Younger Everyday....................32

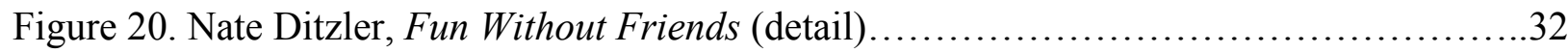

Figure 21. The Royal Art Lodge, In Her Room, Crying, n.d..............................33

Figure 22. Miriam and Ezra Elia, The Diary of Edward the Hamster 1990-1990...............34

Figure 23. William Wegman, To Hide His Deformity He Wore Special Clothing, 1971..........35

Figure 24. Nate Ditzler, It's That Easy............................................ 36

Figure 25. Joan Sommers Design, The Simpsons and Philosophy: The D'oh of Homer, 2001...36

Figure 26. Nate Ditzler, All Work and No Play Makes Us Younger Everyday (alternate view)...37

Figure 27. Nate Ditzler, All Work and No Play Makes Us Younger Everyday (detail)............37 


\section{Introduction}

A Case of the Mundanes stems from my research involving material exploration and personally lived experiences (2016, fig 1). The mixed media installation contains a series of six pictorial sculptures. Each sculpture features a biomorphic form in relation to fabricated, and acquired modified objects, which represent simulations of everyday situations. Each sculpture is delineated by a rectilinear backdrop of color painted on the wall behind it (2016, fig. 2). The exhibition investigates how I relate to the world around me. I employ a phenomenological approach to gain a greater understanding of the metanarratives that lie within my everyday lived experiences. I extend this philosophical position in my decision-making regarding the formal qualities and presentation of the sculptural work in the exhibition to open up the possibility for the viewer to experience and relate to the work based on their subjective reality.

In my work, I create tragicomic depictions that simplify complex emotions in accordance with my personal reality. Everyday events often trigger an emotional reaction. Often it is the strange state of mind brought about by an introspective moment, the frustration that comes from realizing our shortcomings, or the exhaustion that comes with striving for self-gratification. Under closer examination, what appears to be unimportant contains an underlying value awaiting discovery. The exhibition emphasizes the importance of understanding the psychological and emotional impact that lie beneath seemingly ordinary and unreflective moments. 


\section{Overview}

As an artist I give a visual presence to the seemingly trivial and overlooked moments of the everyday. The visual language in my work is derived from the simplicity and playfulness of the illustrations found in children's books and single panel comics. I am fascinated with their allegorical approach to simplifying life lessons. This simplification of content lends itself to the economy of information conveyed in my minimalist aesthetic. Further, the relationship between children's books and allegory informs the metaphorical nature of my artwork. Illustrations from sources such as Peanuts (fig. 3), The Tao of Pooh (fig. 4), and Hope for the Flowers (fig. 5) have inspired the development of a central biomorphic character in my situational sculptures.

The biomorphic form (fig. 6) serves as a surrogate in my autobiographical investigation of everyday events. Through handmade ceramic forms, fabricated mixed-media elements, and acquired and modified objects, I construct a synthesis of reality and fiction. Some of these daily experiences include a feeling of bizarre quaintness, such as trying to enjoy the weather while seated on a park bench, or a longing for home while gazing into a photograph that sits above my desk. Often times these moments are of a melancholic nature, causing me to try and find a humorous dimension within them that serves as comic relief.

The diminutive size of the form in relation to its surroundings speaks to a sense of vulnerability and frailty in an overwhelming reality (fig. 7). In employing a disparity in scale, my intention is to reach the viewer with an empathetic connection. In connecting with the humanity of the biomorphic form, the viewer may draw a connection back to the collective vulnerability within the human condition. 
The rudimentary form of the biomorphic character embodies a reduced visual reference to a living being. The form's beige flocked surface pushes further the idea that the form represents a living entity, while the subtle imperfections such as dimples or mild cellulite subvert the idea of the form as a perfect being. Its portliness runs contrary to the idealized environment in which it exists. The meek and unassuming scale of the biomorphic forms speaks to the aesthetic of cuteness to generate an amiable response from the viewer. Similar to the artist Beth Cavener (b. 1972) (fig 8), who uses animals to "mime the subliminal emotional conflicts"1 that underscore the human condition; I use a stand-in for the human figure.

Calling the viewers attention to everyday situations is achieved through the representation of familiar objects. The relationship of the biomorphic form to these objects offers visual clues toward an underlying meaning. In presenting an environment that combines the surreal with familiar everyday objects such as a cloud, a tree swing, or a balloon, I intend to place the viewer in an experiential space to enter into the work based on their own interpretive analysis.

The experiential platform is achieved by placing three-dimensional objects in relation to the viewer so that they are enveloped within the gallery space. In Fun without Friends (2016, fig. 9), a wall mounted tree branch situated at a height of 10 feet, with a swing that hangs inches from the floor, places the viewer within the scope of its physical parameters. In Flight Risk (2016, fig. 7), a cloud suspended from the ceiling, in the center of the gallery, exists in the visual periphery of the viewer. Creating and installation composed of sculptural objects places the viewer in the realm of the work, and creates a more dynamic interaction.

${ }^{1}$ Kathleen Whitney, "Beth Cavener: Subliminal," Ceramics Monthly 63, no. 9 (November 2015): 40, http://ceramicartsdaily.org/ceramics-monthly/article/beth-cavenersubliminal/ 
Throughout the exhibition, I offer color-associated clues to signify the emotive state of the overall installation. The various tones of grey help to set the stage for a somber and melancholic feeling, while other colors bring a high contrast to grasp the viewer's attention. I use the bright and vibrant as well as the cool and mellow colors to offer a visual balance in each composition. The combination of colors also calls attention to specific details within each sculpture.

In The Big Picture (2016, fig. 10), I create a high contrast between the sterile grey and white setting of the simulated interior domestic space with the bright and vibrant blues of the biomorphic form's prosthetic dorsal fin, in conjunction with the photographic image of a wave. The color coordination creates a dynamic formal relationship while offering subtle clues about the possible connotative meaning of the work. The intention is to make a connection in the composition, through the coordination of color, as it pertains to the content of the sculpture.

To create a dialogue with the viewer, I offer an experiential space where multiple meanings can be found within each sculpture, and the exhibition as a whole. This approach corresponds to the phenomenological basis of the work. Maurice Merleau-Ponty's model of existential phenomenology informs my philosophical investigation into the everyday in its capacity to view "Art as a mode of inquiry into some of the most basic questions we can ask about how we experience the world." 2 Through this approach I express my perspective as an open-ended proposition. The open-ended approach I employ is in the interest of creating a conversation with the viewer.

\footnotetext{
${ }^{2}$ Mark Wrathall, "The Phenomenological Relevance of Art," in Art and Phenomenology, ed. Joseph D. Parry (New York: Routledge, 2011), 7.
} 
Much of existentialism is "concerned with questions about how and whether life has meaning." Merleau-Ponty asserts, "All of (phenomenology's) efforts are concentrated upon reachieving a direct and primitive contact with the world, and endowing that contact with a philosophical status." ${ }^{, 4}$ In (Fig. 11) I illustrate the method I used for deriving meaning from my personal experiences.

In creating an installation space, I intend to place the viewer on a platform with the work. "Merleau-Ponty's central preoccupation is the lessons that art can teach us about the nature of our embodied perceptual engagement with the world." In this same respect, it is my intention to place the viewer in an immersive art space that represents the real world, so they might return to it with a heightened awareness. My hope is that the viewer might gain an appreciation for the underlying value in seemingly unimportant moments and realize what can be gleaned from a more conscious awareness in their daily life.

\footnotetext{
${ }^{3}$ Jane Mairs, “Ask the Editor: The Meaning of Existential," Learner's Dictionary, last modified August 9, 2012, http://www.learnersdictionary.com/qa/the-meaning-of-existential.

${ }^{4}$ Wrathall, "The Phenomenological Relevance of Art," 6.

${ }^{5}$ Ibid., 11.
} 


\section{Personal History}

For as long as I can remember, I have been intrigued by an analytical approach to my life experiences. I have a desire to confront things, sort them out and develop a deeper understanding of them. I believe that quality of life is based on quality of thinking. This led to my pursuit of a degree in cultural anthropology with a focus on ethnographic field studies. It seems natural that an analytical approach informs the basis of my creative output. Through the practice of anthropology I learned to appreciate situations and circumstances I didn't entirely understand. In turn, I have found that appreciation leads to understanding.

My upbringing in the rich and culturally diverse context of Hawaii has instilled a value for observing with couth, and acknowledging the importance of different perspectives. As a Caucasian growing up in an environment with predominantly persons of color I was a local, yet also a foreigner. With the role of the participant observer comes an importance for being deferential in the presence of unknown phenomena. Relating to people with a comical demeanor and a sense of lightheartedness was important to getting along with others.

The ability to view things from a humorous perspective is a core value within my comprehensive worldview. This is especially true of my investigation into the everyday. I feel that much of life is an uneventful melodrama, with a plethora of seemingly unreflective and ordinary moments. If the vast majority of life is worth understanding, then why not investigate this grey area of existence? In anthropology I internalized the external world, and as an artist I am externalizing my internal world. My art practice is concerned with autobiographical expression. It is anthropology of my everyday. It serves as a reflexive system of management and reflection to depict existential gloom with jest. 
I have always used my sense of humor to relate to people I engage, whether it is the clerk at the supermarket, my colleagues, authority figures, or friends. Humor is at the root of my being. Art critic Peter Schjeldahl's quote about artist William Wegman really encapsulates the way in which I view myself, and the art I make as an extension of who I am. "The man told jokes, because when you don't know to whom you are talking or why, it is prudent to be charming. Maybe the attending strangers will laugh, and that will be a temporary deliverance. At least, they will see that you are harmless.",6

My art making practice serves an internal imperative. Through art that uses humor to respond to the everyday, I hope to develop a greater understanding of my own being and how I relate to the world. Further, it functions as a way of connecting with the viewer about who I am. I feel that an artist's audience finds them, rather than an artist choosing to whom it is they appeal. Thus, I find my audience and my place in the world through my artistic expression.

${ }^{6}$ Peter Schjeldahl, "Paintings: The New Wegman," in William Wegman: Paintings, Drawings, Photographs, Videotapes, ed. Martin Kunz and David A. Ross (New York: Harry N. Abrams, 1990), 181. 


\section{Aesthetics of Accessing and Activating the Space}

I use the rectilinear backdrops of color in each composition to activate the gallery space and create a dynamic formal relationship between the two-dimensional plane of the wall and the three-dimensional objects. I create an installation space in conjunction with the notion of art as an expanding field, blurring the distinction between painting and sculpture. Visually, the color blocks are reminiscent of the way artist Peter Halley uses basic geometric color blocks to denote prisons or cells which function as spaces for isolation, contemplation, or reflection ${ }^{7}$ (fig. 12). The rectilinear color backdrops in my exhibition offer the viewer a point of reference or gateway to access the work from one or more vantage points. In offering the viewer more than a single point of perspective, it is my intention to play with the very idea of perspective on a physical and conceptual level. This enables the viewer to engage the work and explore it in whatever capacity that they please.

I use ideas from Minimalist sculpture as a platform to create the contextual setting for the biomorphic forms. As formal consideration, the minimalist approach serves the idea of simplifying complex emotions and provides a direct conveyance of the subject matter. I use forms that are reminiscent of Minimalist icon Robert Morris (fig. 13) which allow me to access and activate the space in instances such as Sweater Weather (2016, fig. 14), Flight Risk (2016, fig. 15), and The Big Picture (2016, fig. 16), where I re-contextualize them into simplified representations of a grassy knoll, a sidewalk, and a living room space. Morris's "Wedge forms,

\footnotetext{
${ }^{7}$ Karlyn De Jongh, "Peter Halley: Conversation with Karlyn De Jongh," in Personal Structures: Time Space Existence, ed. Peter Lodermeyer and Marina Abramovic (Cologne: DuMont, 2009), 276-281, transcribed at: http://www.peterhalley.com.
} 
ramps, and architectural elements that negotiate corner and walls," ${ }^{\prime 8}$ are similar to the visually minimalist language also found in the idealized representations in children's book illustrations and single panel comics. This creates a syncretic agreement between the formal composition and the conceptual idea of simplifying complex emotions.

In reducing the amount of visual information, I use simplified representations of everyday objects to create a simulated setting. This economy of information is visible in instances such as a tree represented by a single fabricated tree branch in Fun without Friends (2016, fig. 17), or a domestic interior space as represented by stenciled wallpaper in The Big Picture (2016, fig. 10). In minimizing the visual information given, I simplify the issue being addressed while presenting it with a degree of ambiguity. The intention is to open the possibility for interpretation by the viewer, while also offering an immediate understanding as to what the work represents.

Artist Charles Ray's Fire Truck (1993, fig.18) employs the same notion of simulacrum and simplification. Ray's representational works often have a surreal quality, while offering enough visual information to be understood on a base level. Like Ray's sculptures, my work intends to leave room for the viewer's interpretation through subtle ambiguity.

${ }^{8}$ Robert Pincus-Witten, PostMinimalism (New York: Out of London Press, 1977), 190. 


\section{Words and Imagery}

The relationship between words and imagery provides an opportunity to add another dimension of meaning to an artwork. In connecting textual and visual information, I am able to give further inferences to the emotional value, intellectual inquiry, or the element of humor. Titles can offer clues to the viewer about the meaning of a work, subvert its visual signifiers, or build on an already enigmatic visual presence of a work.

My use of the pop culture term "sweater weather", as a title for one of the sculptures in my exhibition, could have a multitude of connotative meanings for the viewer depending on the associations that they attribute to it. Whether it connotes coziness, loneliness, or is appreciated for the simple notion that it rhymes, is entirely up to the viewer. In The Big Picture (2016, fig. 10), I use a double entendre as a seemingly flat-footed title for a sculpture that features a large picture in relation to the biomorphic form gazing upon it. In All Work and No Play Makes Us Younger Everyday (2016, fig. 19), I create an oxymoronic statement that refers to the blending of two disparate ideas into one activity. The viewer's takeaway will likely differ to some extent, yet making jest of the workaday is something to which most people can relate. In Fun Without Friends (2016, fig. 20), I offer conflicting textual information to the sad imagery of a biomorphic form slumped over a tree swing. In the case of each sculpture, the relationship between text and image relates back to the aesthetic of single panel comics, children's books, and the element of humor. 
In my exhibition, I use the title of each sculpture to offer supplementary information to the viewer. I derive this sensibility from the Canadian collaborative artist group The Royal Art Lodge. Their frequent use of captions that relate to the imagery in their drawings and paintings offers insight into the work, which lies between the two sets of information.

The Royal Art Lodge is a major artistic influence on my work and has shaped the way I think about the relationship between text and imagery (fig. 21). The collaborative group of artists also use text as "The vehicle for the humorous aspect, functioning like a concluding action to reveal the "sense" of the scene: like a melancholic but wise voice-over, telling us that sense is pure nonsense, a tragicomic jest about life and it's painful bullying." " In this same respect, the titles for my work function as a deadpan punch line in conjunction with the visually melodramatic appearance of the work.

One literary work worth mentioning here is "The Diary of Edward the Hamster 19901990." In the foreword of the book, I find a parallel in the way I use allegory to depict everyday banalities, which hint at larger universal metanarratives in the human condition (fig. 22).

"It is an extraordinary work: profound meditations on the nature of captivity and the soul, interlaced with stark reflections on the grinding banalities of everyday living, illuminate its tiny pages. Edward unpicks the very fabric of tedium and forces us to question the drive that leads any of us to first take inky straw to paper. His short life is here set down in its entirety, yet his voice will surely echo through centuries to come. If you take the time to read this intense but intimate journal, you may come to realize that Edward is not just a hamster; he is a state of mind."

${ }^{9}$ Guido Bartorelli, The Royal Art Lodge: 13 de Junio al 28 de Septiembre de 2008, Centro de Arte Daja de Burgos (Burgos, Spain: Caja de Burgos, 2008), 9.

${ }^{10}$ Miriam Elia and Ezra Elia, The Diary of Edward the Hamster 1990-1990 (New York: The Penguin Group, 2013), 2. 


\section{Layers of Meaning}

By employing a whimsical approach to intellectual inquiry, I seek to make complex subject matter more accessible. I use humor as a point of entry to create a surface layer of understanding, while hinting toward the underlying seriousness in my sculptures.

Similar to the early work of William Wegman (b. 1943), I intend for meaning to be found on different levels ${ }^{11}$ (fig. 23) in my work. As an artist making highly personal work, I must also consider the viewer. I believe that art exists to create conversation, and that it ought to be accessible on some level. In It's That Easy (2016, fig. 24), I situate a biomorphic form with a tow strap chained to a proportionately enormous rock with a plaque that reads "Kindness". In this sculpture, I am addressing the issue of interpersonal communication in the everyday. It speaks to my personal experiences regarding the extreme difficulty of always engaging people with tact and consideration. Though the sculpture is autobiographical, I offer enough information for the viewer to glean that the virtue of kindness is not always easily exercised.

Through metaphorical depictions I seek to give visibility to the psychological and emotional states I experience in the everyday; I intend for the audience to link my visual metaphors to their own subjective reality. In using visual language derived from children's books and single panel comics, I hope to reach a broader audience including children, laypersons, as well as those who have a background and understanding of visual art. In Flight Risk (2016, fig. 7), a biomorphic form stands at the edge of a sidewalk as a balloon floats toward the ominous grey cloud that looms at the center of the gallery.

\footnotetext{
${ }^{11}$ Peter Weiermair, "Photographs: Subversion through the Camera," in William Wegman: Paintings, Drawings, Photographs, Videotapes, ed. Martin Kunz and David A. Ross (New York: Harry N. Abrams, 1990), 45.
} 
In this sculpture, I am expressing the sense of loss that I felt about the death of a close friend. I use the balloon to metaphorically depict the inevitability of loss, and the inherent quality of impermanence in the human condition. Though the idea of loss exists on a spectrum of severity, the viewer will likely be able to understand the signifiers in the composition hinting at loss and the resulting despair.

Like the television show The Simpsons, there are adult understandings to be gained through seemingly sophomoric humor. For example, in the book The Simpsons and Philosophy: The D'oh! of Homer (fig. 25), a multitude of philosophical dispositions are expressed through the characters, themes, and situations in the pop culture cartoon. In Why Maggie Matters: Sounds of Silence, East and West, Maggie's character relevance is discussed within the framework of eastern philosophy and what we might stand to learn from observing more and saying less. ${ }^{12}$ In this same respect, I combine a juvenile visual language to explore a more complex underlying meaning.

For the more initiated viewer, I offer clues about my artistic influences. I also make subtle inferences toward my sense of humor and affinity for parody. As mentioned in an earlier section of this thesis, I use the architectural forms reminiscent of Minimalist icon Robert Morris to access and activate the gallery space. In Morris's installation in the Green Gallery in NewYork (1964, fig. 13), he used the large geometric plywood forms in a way that "firmly joins art to its environment, inviting the viewer into the sculpture." ${ }^{, 13}$ In my thesis exhibition, I use

\footnotetext{
${ }^{12}$ Eric Bronson, "Why Maggie Matters: Sounds of Silence, East and West," in The Simpsons and Philosophy: The D'oh! of Homer, ed. William Irwin (Chicago: Open Court Publishing, 2001), 29.

13 "Talking to the Listening Tree," Art Journal for BA Art, Chelsea Art College, University of Arts London, posted on November 1, 2011 https://talkingtothelisteningtree.wordpress.com/2011/11/01/minimal_art/
} 
forms similar to those of Morris's to stage a melodramatic comedy with my surrogate in the spotlight, yet with no play to perform. ${ }^{14}$

14 Jorg Heiser, All of a Sudden: Things That Matter In Contemporary Art (New York: Sternberg Press, 2008), 38. 


\section{Instigations, and the Process of Making}

In the thesis exhibition consisting of six individual sculptures connected by a common figure (the biomorphic form), I explore the underlying value of experiential phenomena in the everyday. The themes explored in the exhibition are indicative of human foibles and frailty. Specifically, the sculptures are individually concerned with notions of making the best of adverse or undesirable situations, loneliness and loss, achieving balance, a sense of belonging, and interpersonal relations. The themes are recurrent and have been central to my graduate research.

Applying humor to my lived experiences is the jumping off point in my process of making art. Bringing a sense of lightheartedness to harsh moments of realization makes them more manageable, and allows me to reflect on the possibility of an underlying meaning. As a visual thinker, I reorganize the event into an abstraction. I re-contextualize the event into a mental image, like a still from a cartoon or comedy sketch. The mental image is then made into a sketch on paper, which I use as a reference point to work out what materials are needed to make a three-dimensional sculpture. The sculpture is content based while material choices are based on what is physically required of a sculpture. Whether an object must be load bearing, lightweight, or designed to bend, is decided in the design phase. As a mixed media artist, I don't have any inclinations toward any particular medium. As artist Tony Matelli has said, "Materials are there to serve ideas." ${ }^{.15}$

15 Robert Preece, "Human Echo: A Conversation With Tony Matelli," Sculpture 33, no. 1 (January/February 2014). http://www.sculpture.org/documents/scmag14/janfeb_14/fullfeaturetony-matelli.shtml. 
In All Work and No Play Makes Us Younger Everyday (2016, fig. 26), I depict a biomorphic form using another biomorphic form as a fulcrum. The exaggerated lever lodged under an enormous grey rock bends in this suggestively futile effort by the biomorphic forms to move the rock. The sculpture might also be understood as a teeter-totter, with a rock at one end and a biomorphic form on the other. In this enigmatic yet somewhat familiar depiction combining ideas of work and play, I am addressing the conundrum within my efforts as an artist. The process of making is exhilarating and simultaneously exhausting. Some efforts prove futile, and never come to fruition.

For this composition to work visually, the lever or plank really needed to flex to convey a sense of tension. The process of continually planing (shaving down) the plank until it acquired the degree of flexibility required, calls for the tedious process of alternating back and forth between planing and setting up the sculpture. The choice of using an actual rock for its weight was necessary to effectively create the ten-foot cantilever of the plank. The biomorphic form that serves as the fulcrum, needed to fit the angle of the plank that flexes over its back for the composition to make sense visually (fig. 27).

I begin making the biomorphic forms by filling a balloon with plaster, which has been mixed with water. In the five minutes that it takes the plaster solution to harden, I am able to manipulate it into a form that suits the situation, which it must physically fit, for the sculpture to work as a composition. This affords me a relatively quick means of figuring out how to use an amorphous form to suggest a gestural anthropomorphic entity. The balloon serves as a membrane for the plaster solution, which has the perfect physical consistency to flow naturally so that it can be manipulated with ease. 
Using the plaster form as a model for the composition, I then replicate them in clay using a pinching technique. Clay comes with a set of challenges as well as advantages for making this work. The pinching technique allows me to create gestural subtleties in the form and surface such as folds or dimples. I do this in an effort to give the viewer a greater sense that the forms are life like. The clay forms are then fired in an electric kiln, transforming them into ceramic forms. I use a commercial beige-tan nylon flocking for the surface of each form. This surface is used as a means of getting the viewer to respond empathetically to the forms, as they might to a small animal.

I use a rudimentary form with a color neutral surface to offer continuity throughout the exhibition, so that the viewer might conclude that each sculpture is depicting the same entity in different circumstances or situations. The beige-tan nylon flocking I use is typically used for decoys in sport hunting. I use this specific surface treatment to represent the biomorphic forms as vulnerable beings, like an animal of prey. I am alluding to vulnerability in the human condition in general, and specifically to the emotional impact of my own experiences. The inference between the general human condition, and my specific experiences, is signified by the generic yet specifically nuanced nature of the form in each sculpture. The rudimentary form gives the viewer more psychological room to project their own ideas about what the form represents to them personally.

I use the biomorphic form for its ability to convey the basic idea of a living entity. People are generally sympathetic to the idea of other living things, so the form serves as a vehicle for empathetic connection with the viewer. In an effort to connect empathetically with the viewer, my intention is for them to possibly draw a connection back to themselves or the 
larger notion of humanity as a whole. Though I am depicting circumstances that are referential to my own specific experiences, they also speak to experiences that other people can relate to.

In each sculpture the biomorphic form exists within the context of a hypothetical situations. As the centerpiece of each sculpture, the biomorphic forms are the objects with which the pictorial-sculpture is concerned. The subject matter of each sculpture is supported by the contextual clues offered by the representational objects with which it is engaged. The use of fabricated and acquired modified objects plays back into the idea that the sculptures are depictions of the everyday, yet in a fictitious setting.

To create an immersive installation environment within the gallery I built a model of the space and each object within it. Creating a maquette of the gallery space and each sculpture at 1:24 scale allowed me to see how the space would be used most effectively. The maquette also helped to figure out the placement and orientation of each sculpture in relation to the viewer's interaction.

The simplified geometric and architectural forms were designed to fit in specific places and spaces within the Laura Mesaros Gallery. The minimalist sculptural forms serve as contextual platforms within each sculpture. Individually, they represent common everyday spaces such as a grassy knoll, a sidewalk, and an interior domestic space. In the exhibition I sought to go beyond the idea of sculpture as a discrete object by activating the space with the forms that were specifically designed to add a situational context. 
To simulate everyday situations through representational objects, a myriad of fabrication techniques were required. Most of the representational objects in the thesis exhibition required carpentry skills and were constructed of wood. The tree branch was constructed of laminated $2 \mathrm{x}$ 4s sculpted with power tools. The cloud was made of laminated insulation foam and was sculpted by the same means as the tree branch. The smaller details of some of the sculptures required techniques including casting of resin and silicone with additives. In an effort to give all of the sculptures a clean and simple appearance, a lot of attention to detail was required.

Some of the idealized objects in the exhibition, such as the tree branch, the cloud, and the balloon were sketched on paper as a full size outline of the form. From the two-dimensional outline, I was able to anticipate the other dimensions necessary to make the three-dimensional object. The process of laminating wood, or foam, is how the dimensionality of each object was achieved. Drawing guidelines on the three-dimensional mass, I sculptured by the reductive process of carving, cutting, and sanding them until they were smooth. The balloon was made by the same reductive rough cutting as the tree branch and the cloud, and then was placed on the wood lathe to get a clean finished form.

The surfaces of the objects, which make up the situational contexts in each sculpture, were all painted. Each simulated object was assigned a color to create continuity through out the exhibition. Objects understood to simulate wood were painted with a light wood-like color. The two rocks in the exhibition were painted grey to give the general idea of what a rock looks like in a simulated context. In each case the painted surfaces gave a holistic and visually cohesive feeling to the exhibition. 
To fabricate objects, based on a sketch, involves a lot of problem solving. These issues involved material considerations, the order in which things had to be done, and following a strict timeline. Figuring out the right tool for each task was critical in getting a good finished result. The material exploration that has been central to my graduate research made the execution of my thesis exhibition possible. 


\section{Conclusion}

As an artist I give a visual presence to the seemingly trivial and overlooked moments of the everyday. My thesis exhibition served as an investigation of my personal experiences drawn from mundane, everyday situations. This investigation gave me the opportunity to reflect on my individuality and how I operate in the day to day. I have come to realize that my art is an extension of my personality and reflects my tendency toward a playful, humorous, and analytical disposition to perceived complexities. Perhaps this is a defense mechanism designed to metabolize indigestible moments of hardship. Another consideration is that employing this disposition creates a distance between an event and myself. This distance affords me a vantage point, so that I can see more clearly the underlying meaning and metanarrative in particular moments. 


\section{Figures}

\section{A CASE OF THE MUNDANES}

MASTER OF FINE ARTS THESIS EXHIBITION

MARCH 7-11

Fig. 1. Nate Ditzler, A Case of the Mundanes (Exhibition title), 2016. (Photo courtesy of Laura Konecne).

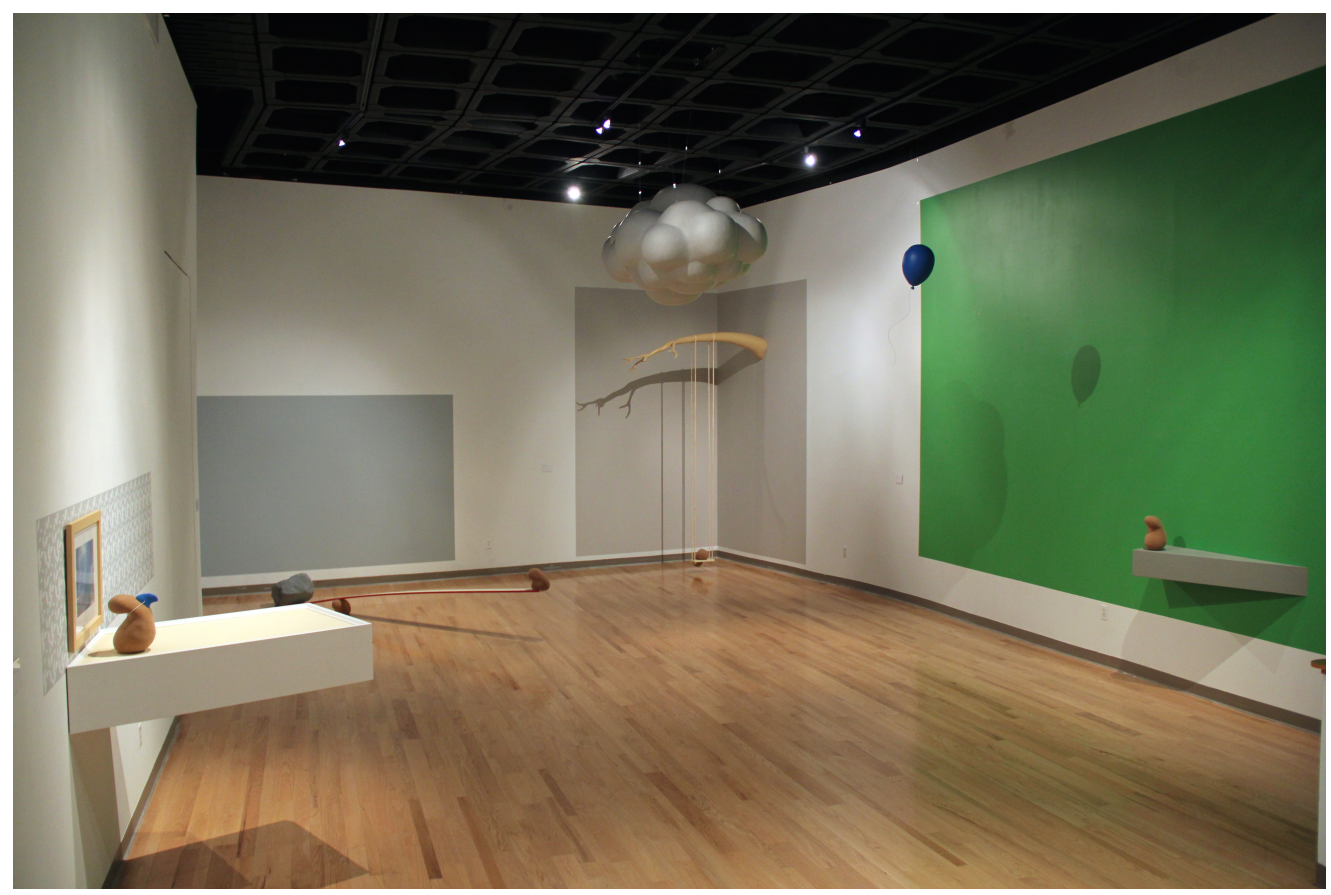

Fig.2. Nate Ditzler, A Case of the Mundanes (Installation view), 2016. (Photo courtesy of Laura Konecne). 


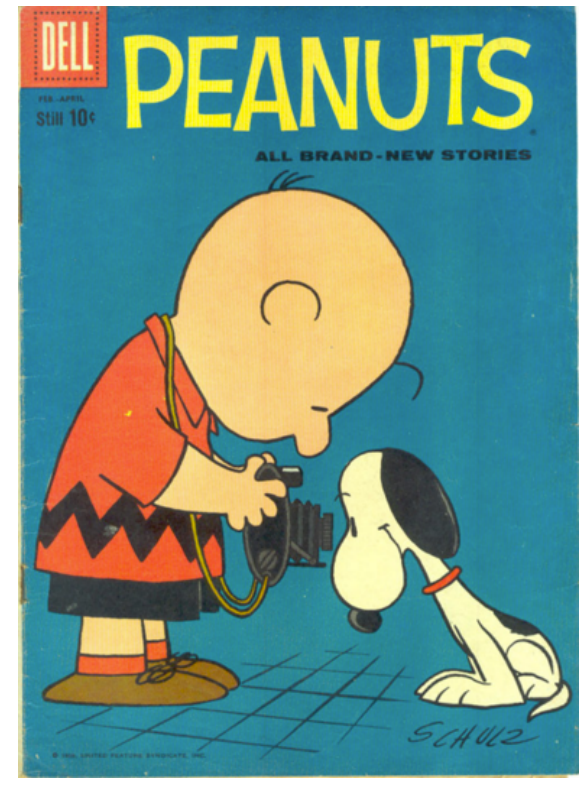

Fig. 3. Charles Schulz, Peanuts Comic, n.d. Reproduced from http://thebluegrassspecial.com/archive/2010/october10/peanuts-dale-hale.php (accessed April 1, 2016).

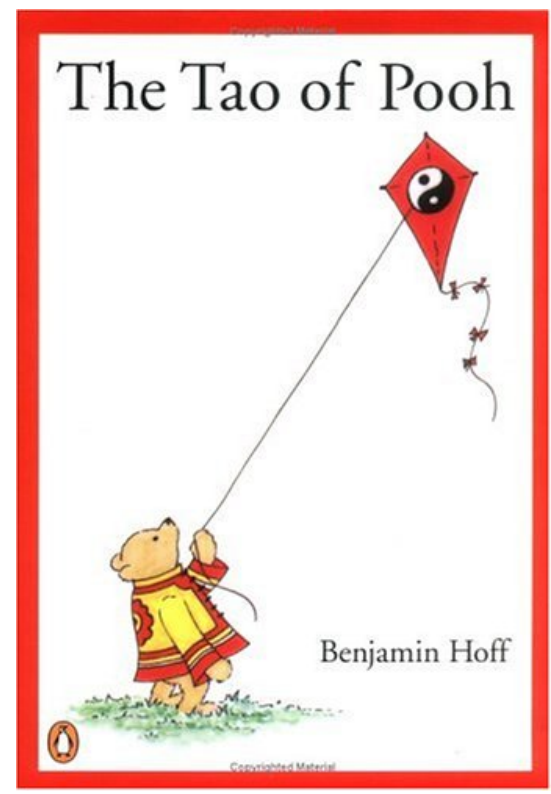

Fig. 4. Ernest H. Shepard, The Tao of Pooh, cover illustration, n.d. Reproduced from https://theblissprojectblog.wordpress.com/2012/05/27/the-tao-of-pooh/ (accessed April 1, 2016). 


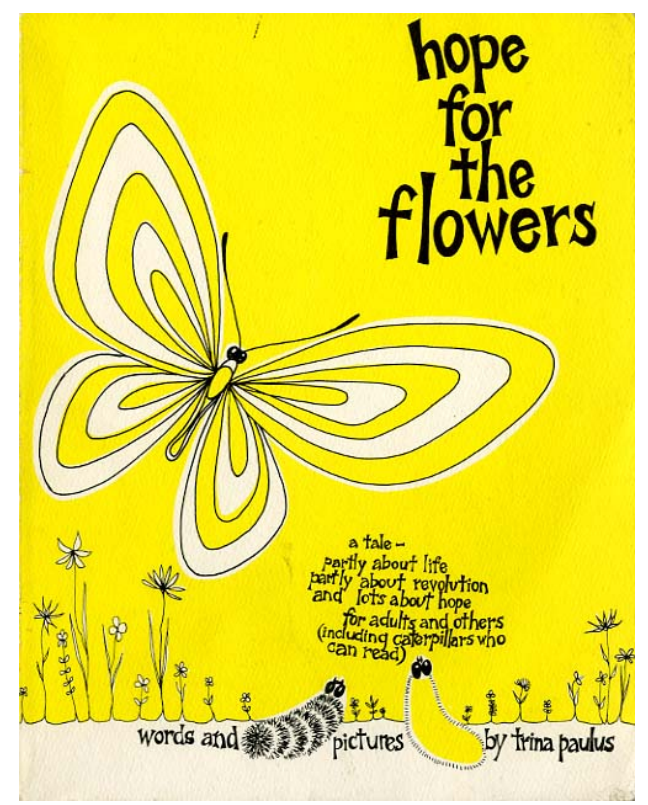

Fig. 5. Trina Paulus, Hope for the Flowers, cover Illustration, 1972. Reproduced from Google Books (accessed April 1, 2016).

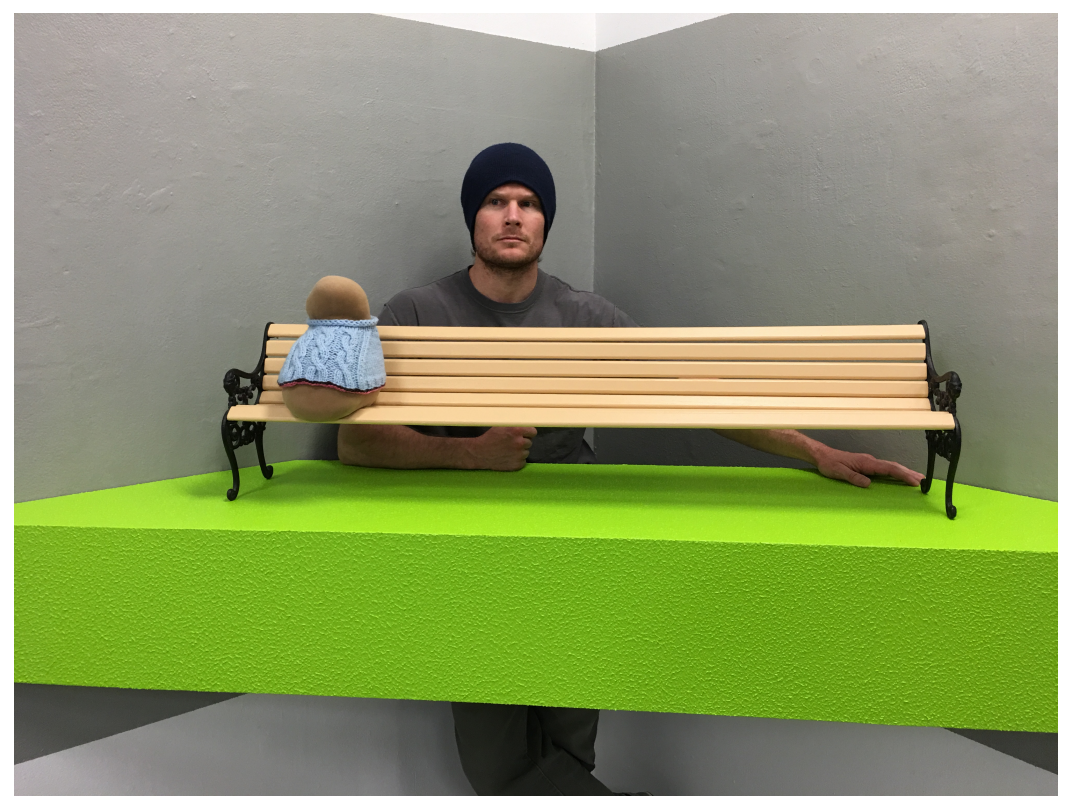

Fig. 6. Nate Ditzler, Sweater Weather (image includes the artist), 2016, ceramic, flocking, wool sweater, wood, acquired modified object (iron), paint. Dimensions variable. (Photo courtesy of Laura Konecne). 


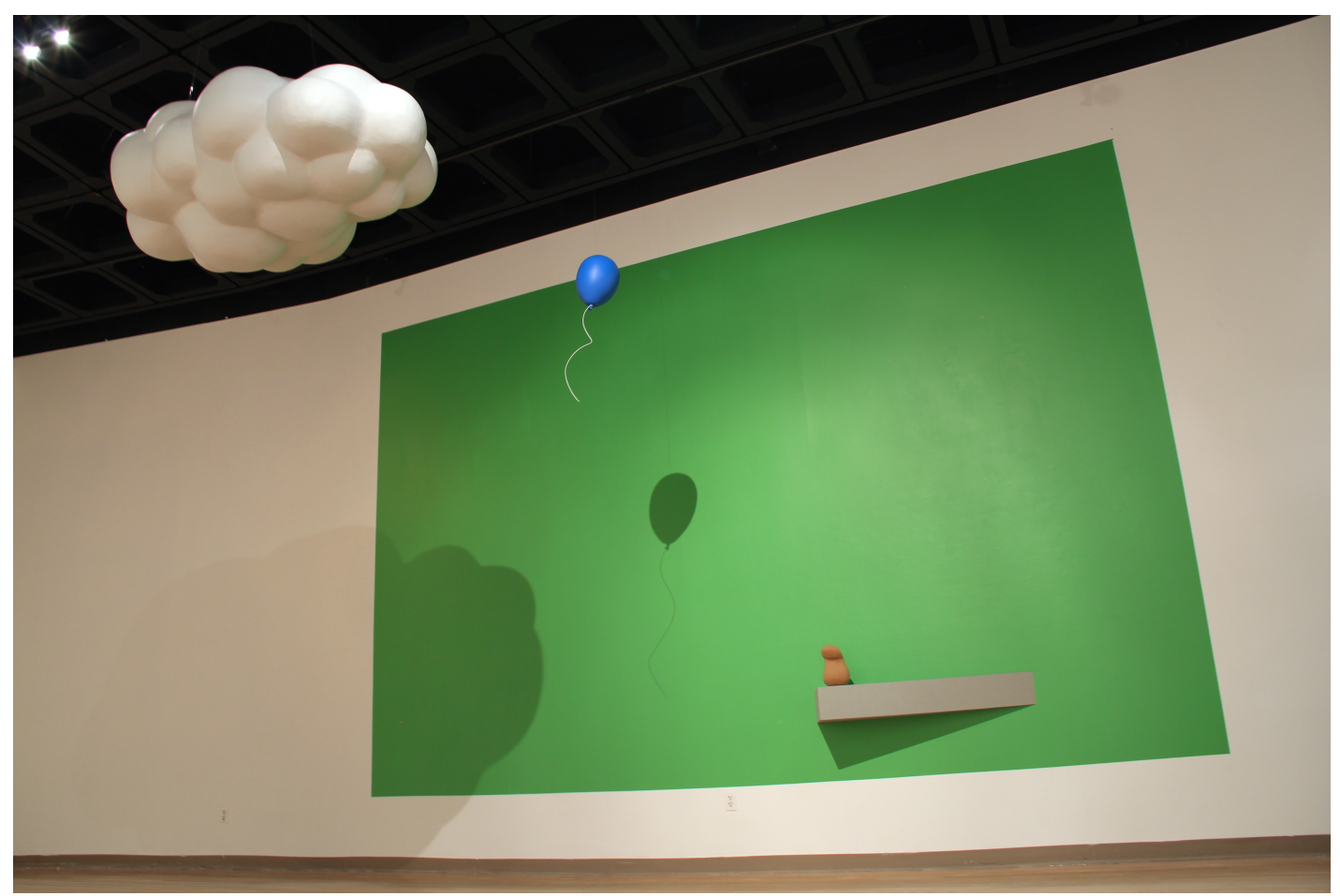

Fig. 7. Nate Ditzler, Flight Risk, 2016, ceramic, flocking, foam, wood, metal wire, paint. Dimensions variable. (Photo courtesy of Laura Konecne).

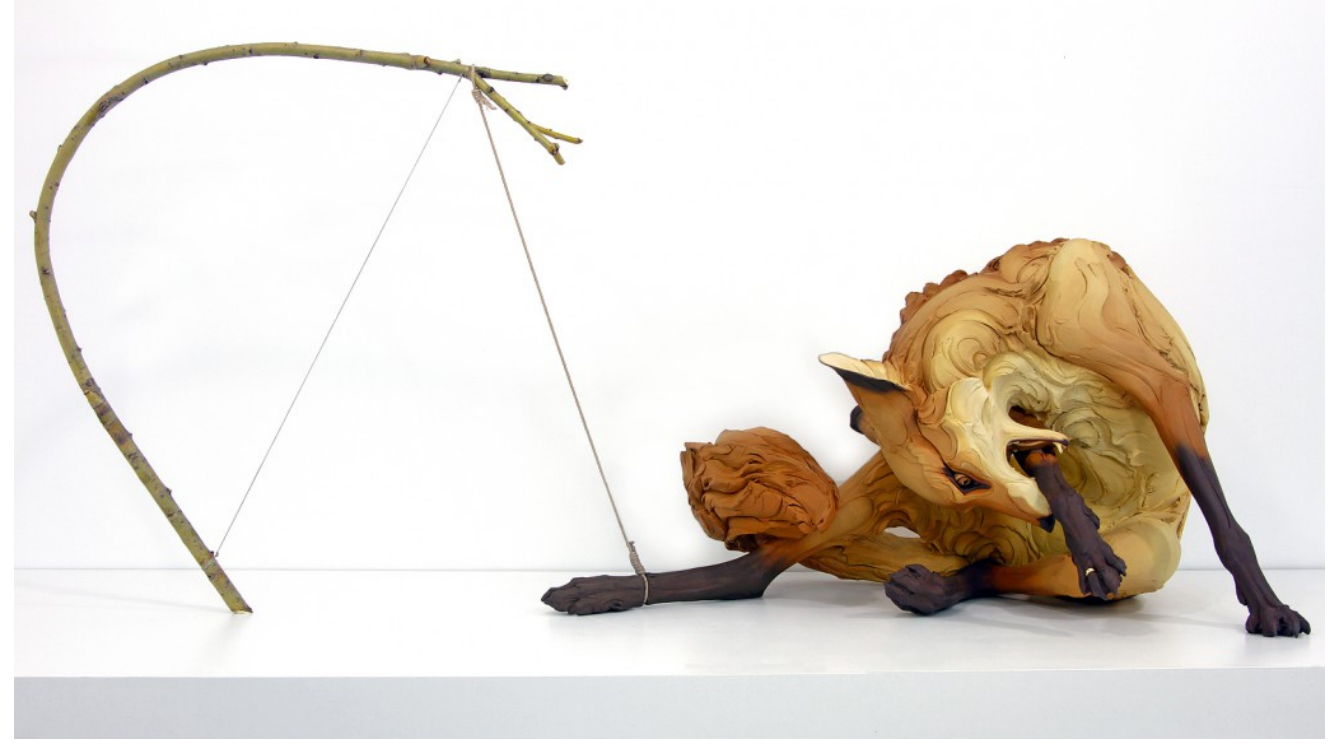

Fig. 8. Beth Cavener, Trapped, 2015, stoneware, paint, 18k gold, rope, wood. 37 inches. Reproduced from http://www.followtheblackrabbit.com/upcoming-exhibitions/ (accessed April 1, 2016). 


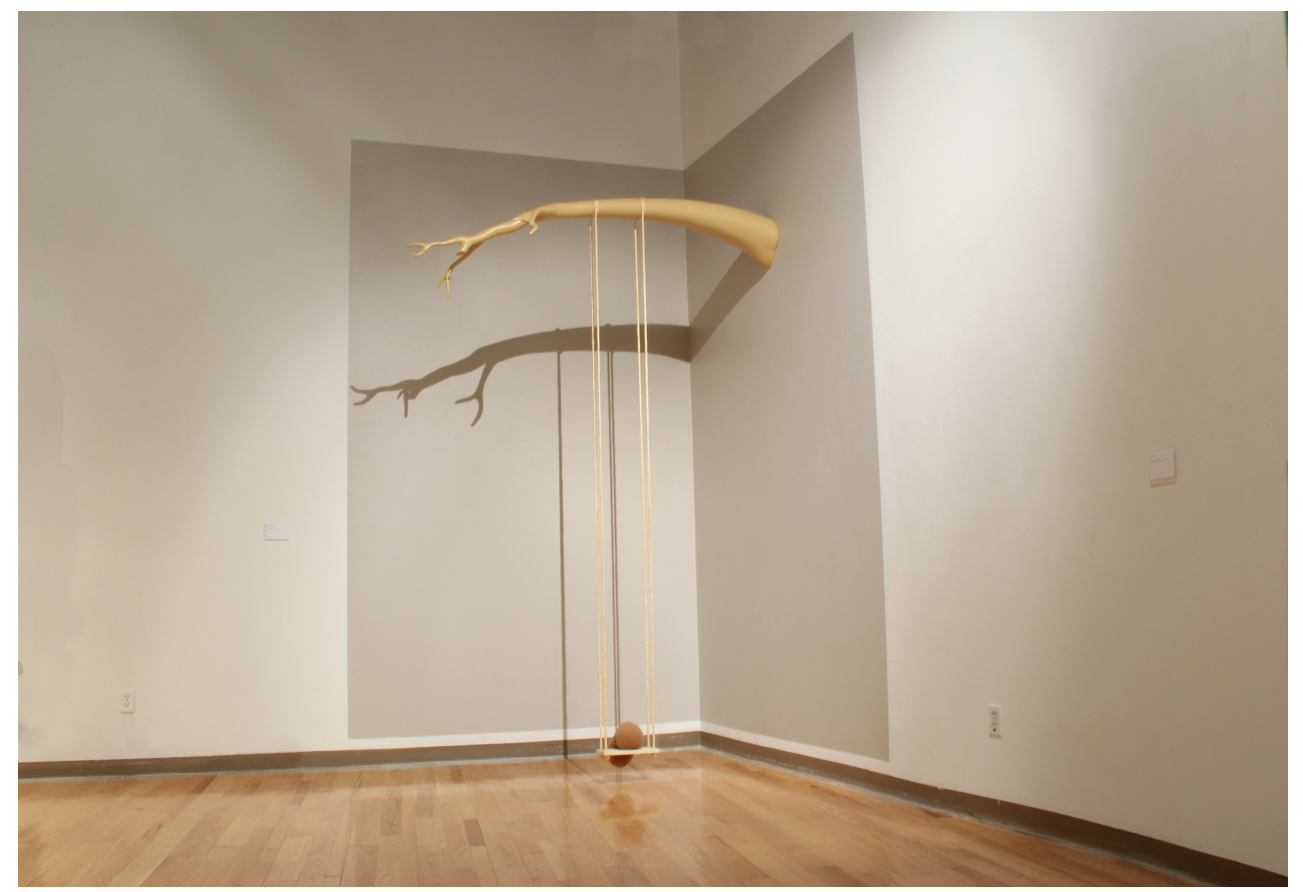

Fig. 9. Nate Ditzler, Fun without Friends, 2016, ceramic, flocking, wood, dyed rope, paint. Dimensions variable. (Photo courtesy of Laura Konecne).

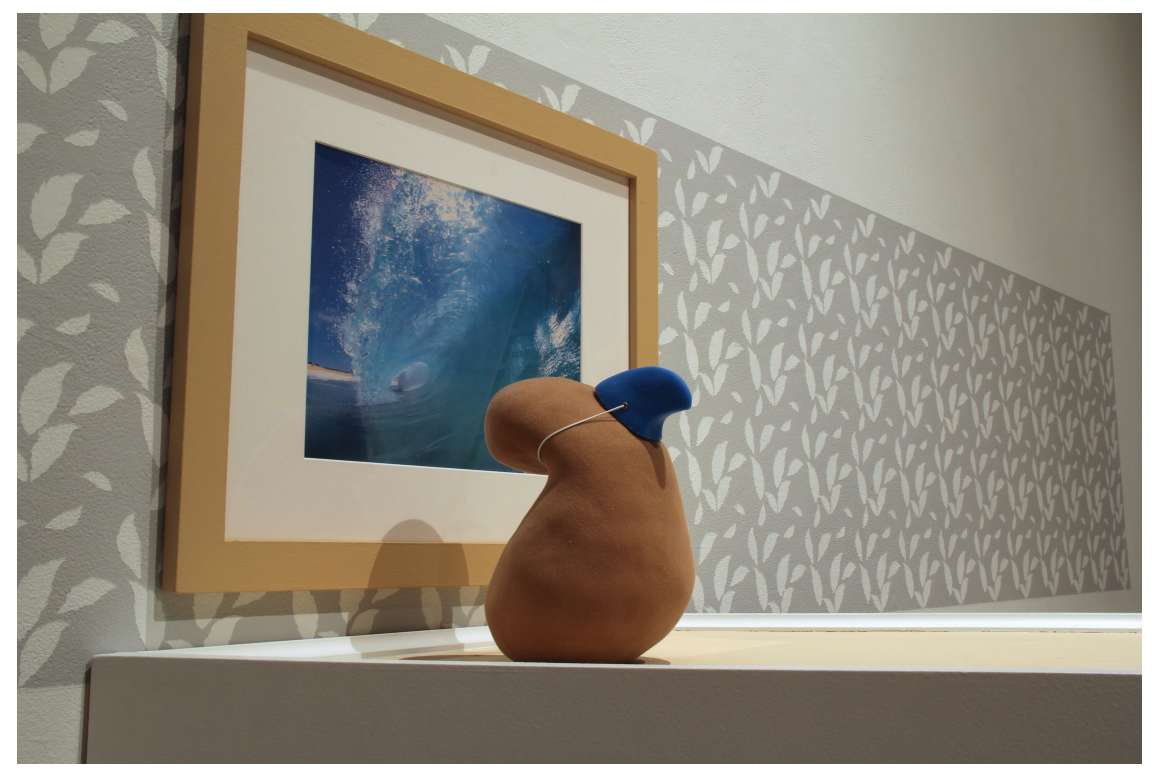

Fig. 10. Nate Ditzler, The Big Picture (detail), 2016, ceramic, flocking, wood, acquired modified object (photograph), cast silicone, elastic string, paint. Dimensions variable. (Photo courtesy of Laura Konecne). 


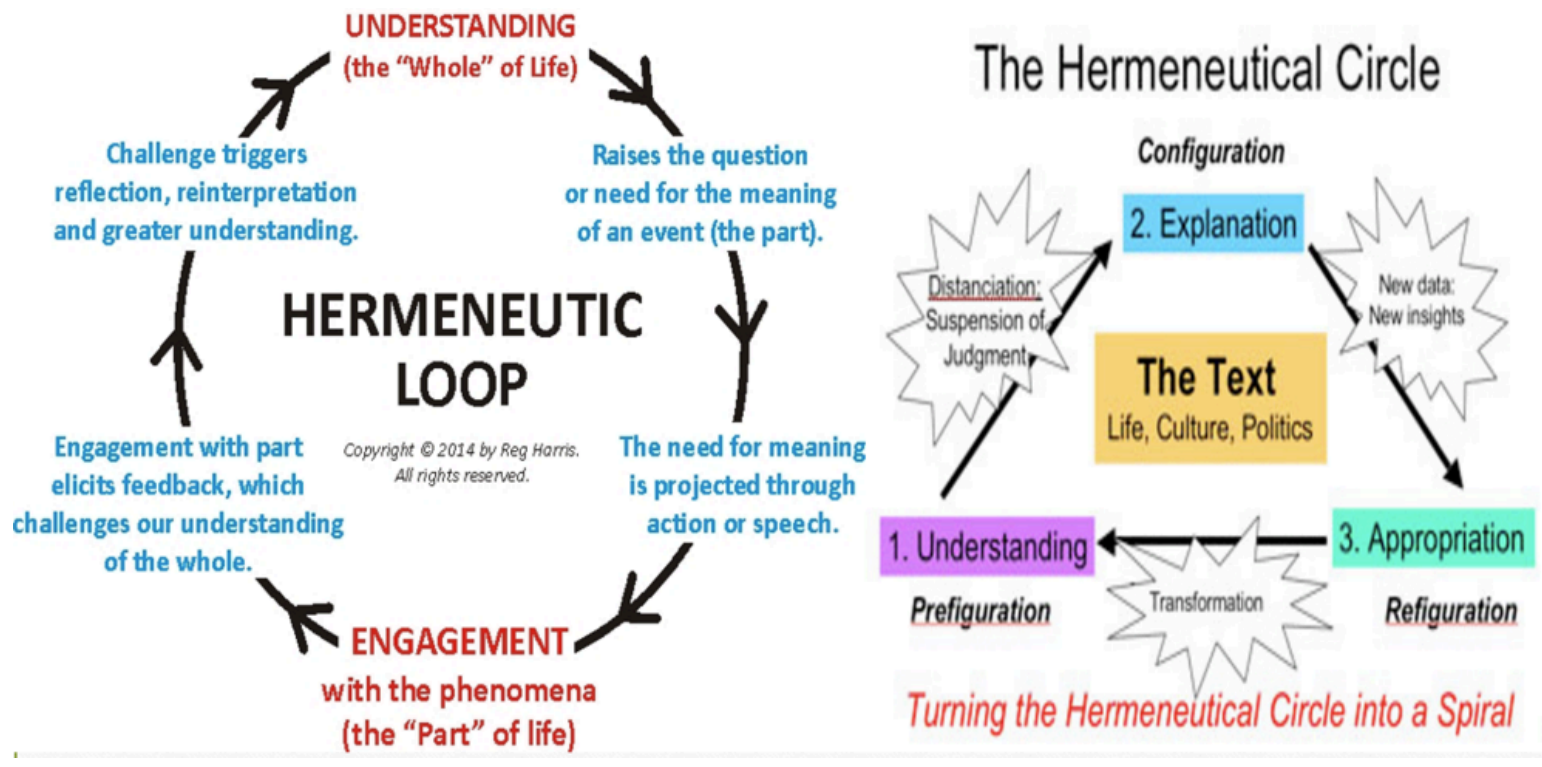

Fig. 11. Hermeneutic Cycle. Martin Heidegger. Reproduced from https://gizellacalingo.files.wordpress.com/2014/11/tgtgtgtg.png (accessed April 1,2016).

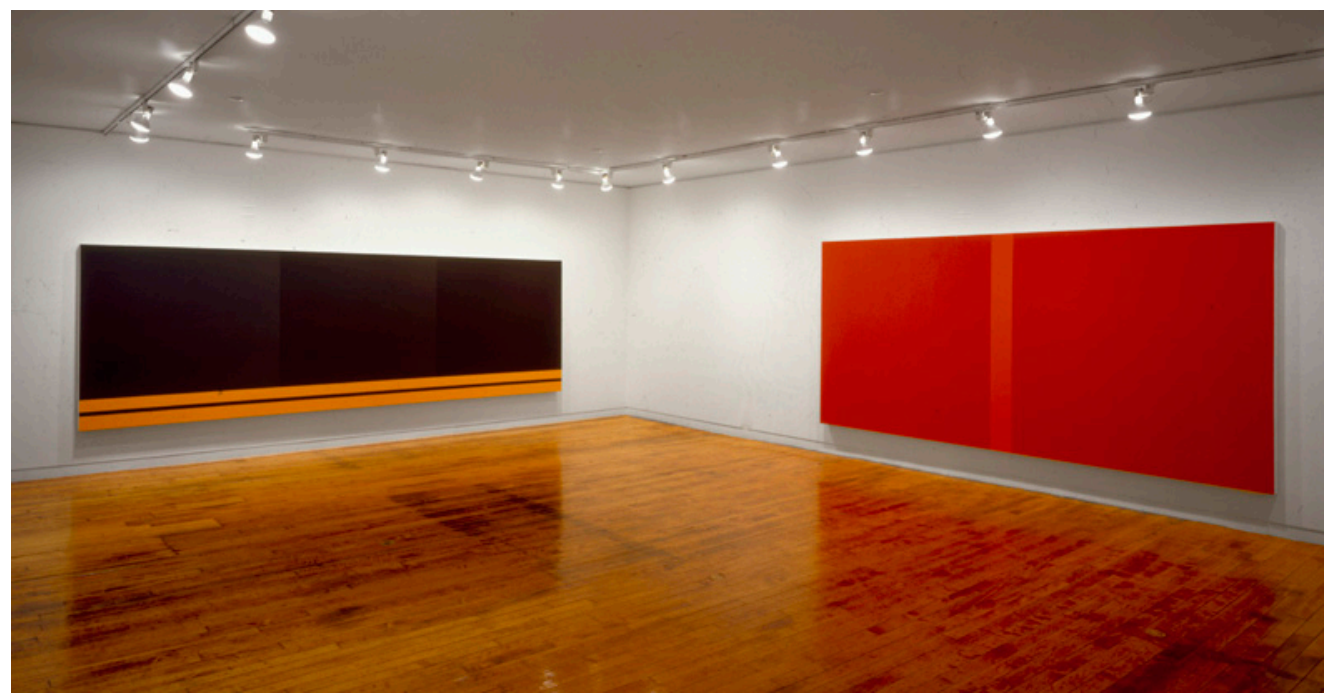

Fig. 12. Peter Halley, Sonnabend Gallery, New York, 1987. Reproduced from http://www.peterhalley.com/ (accessed April 1, 2016). 


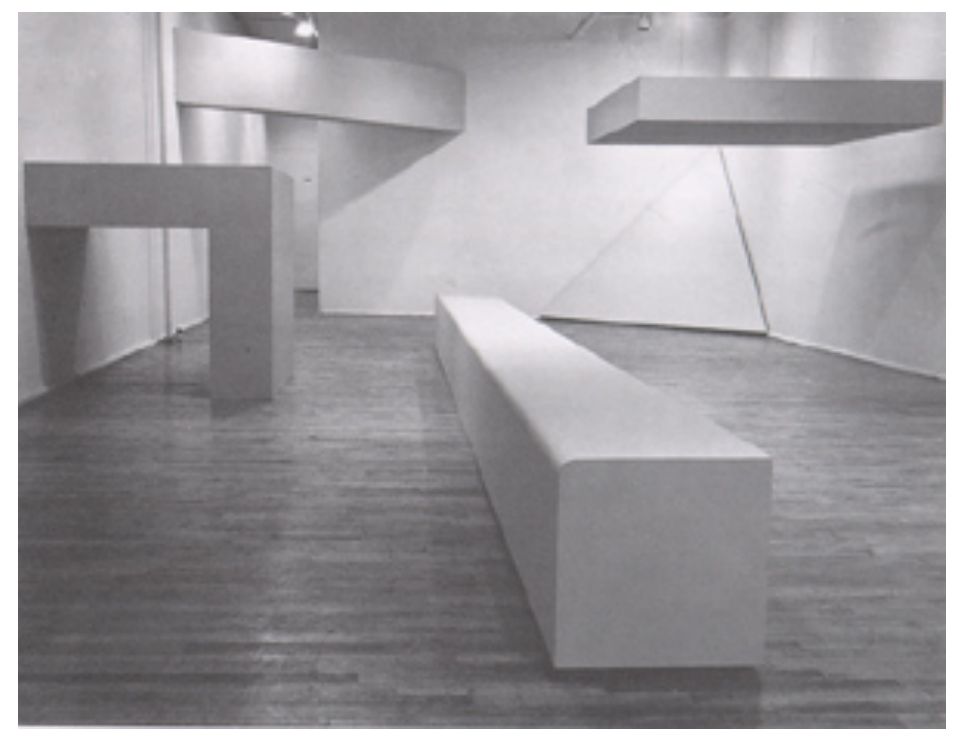

Fig. 13. Robert Morris, "Installation view of one person exhibition" at the Green Gallery, New York, 1964. Reproduced from http://rodin.cda.ucla.edu/winter2001/design160/students/hwkim/Web\%20Page/west.html (accessed April 1, 2016).

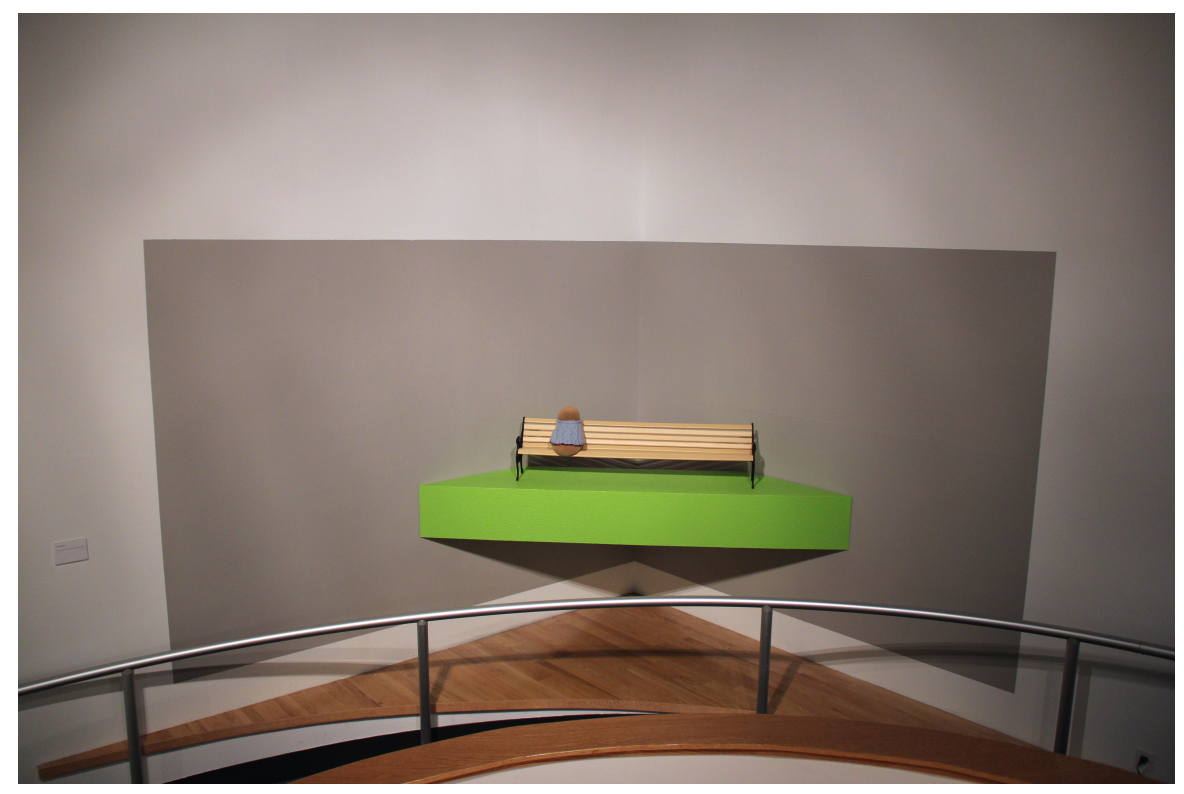

Fig. 14. Nate Ditzler. Sweater Weather (Installation view), 2016, ceramic, flocking, wool sweater, wood, acquired modified object (iron), paint. Dimensions variable. (Photo courtesy of Laura Konecne). 


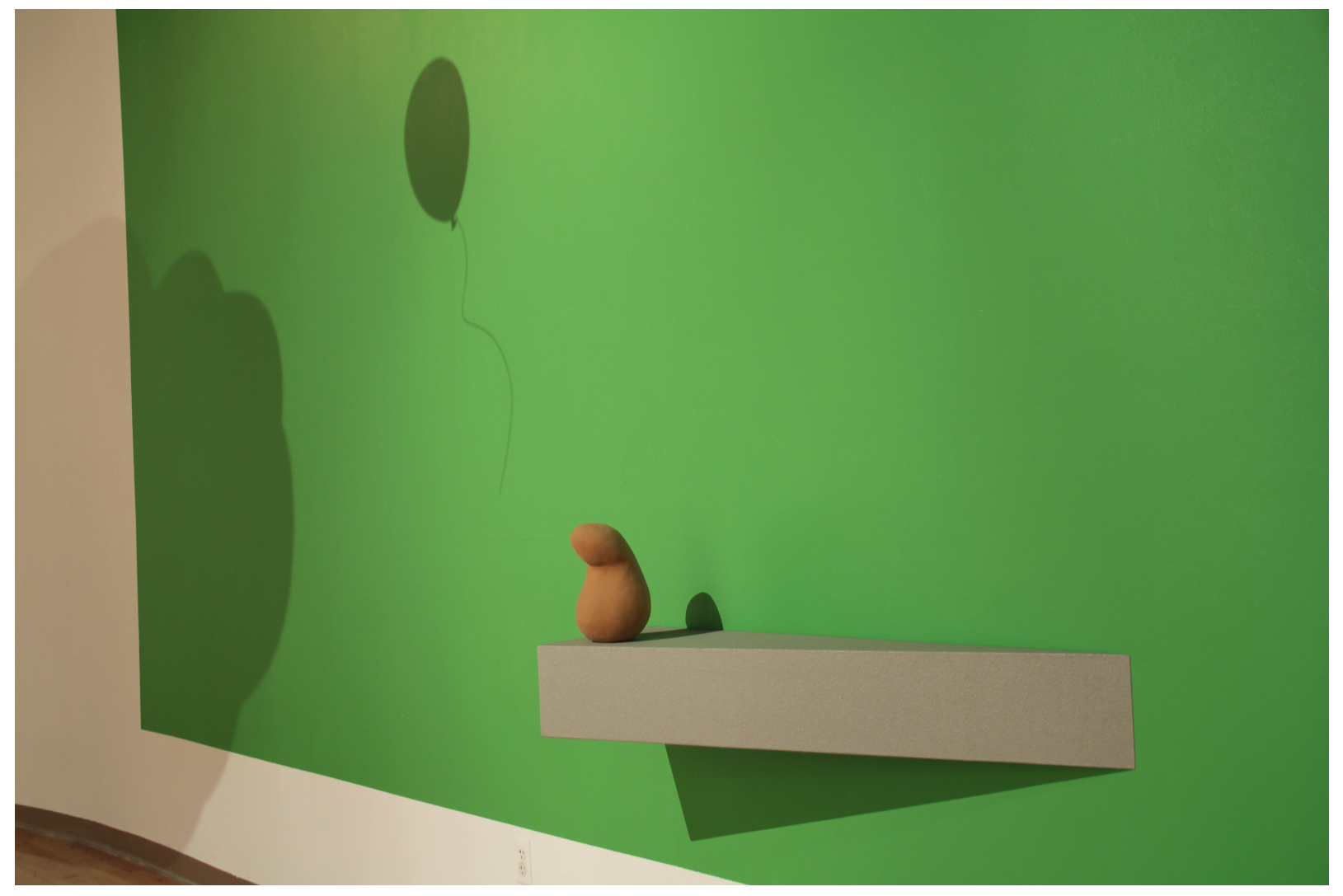

Fig. 15. Nate Ditzler, Flight Risk (detail), 2016, ceramic, flocking, foam, wood, metal wire, paint. Dimensions variable. (Photo courtesy of Laura Konecne). 


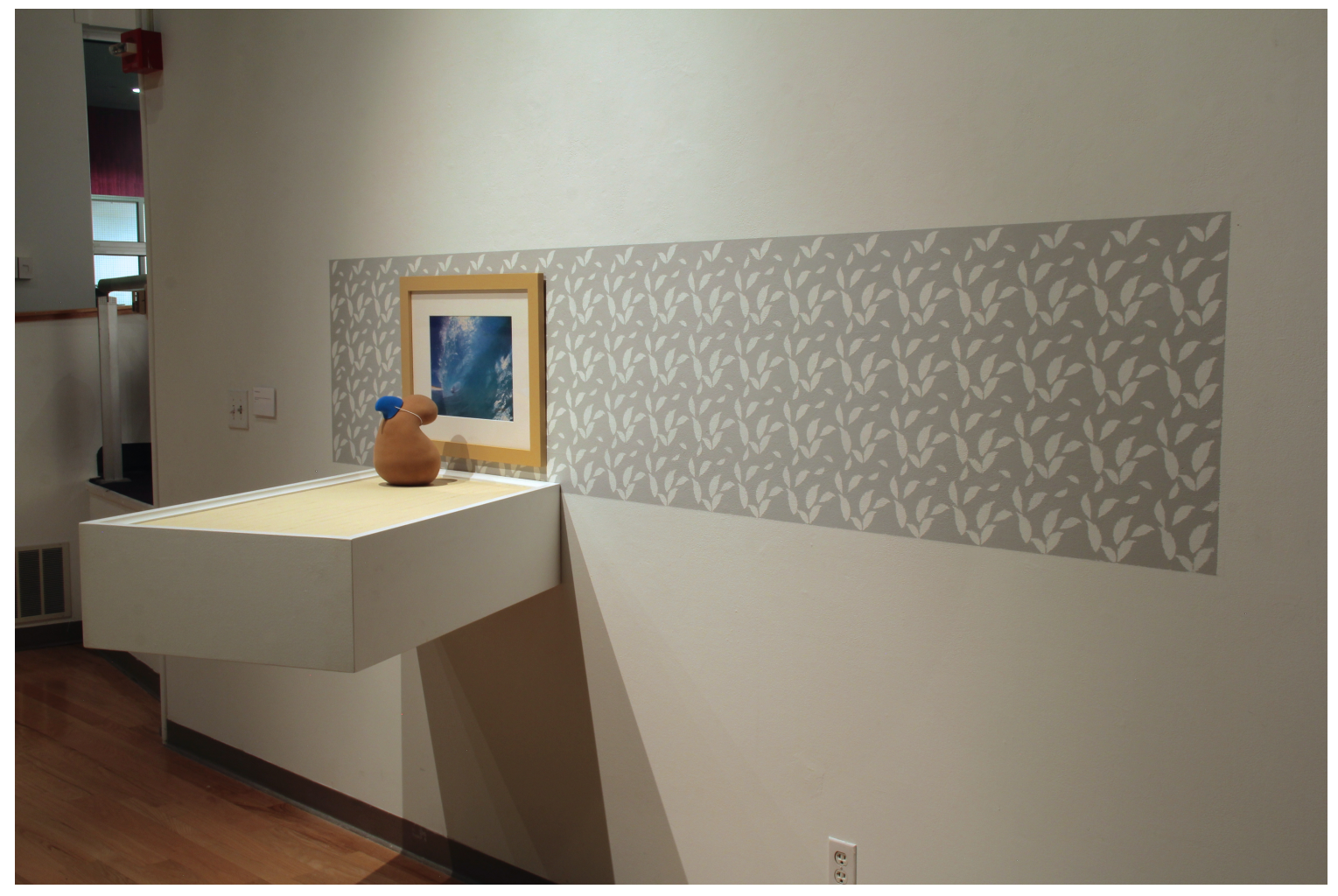

Fig. 16. Nate Ditzler, The Big Picture, 2016, ceramic, flocking, wood, acquired modified object (photograph), cast silicone, elastic string, paint. Dimensions variable. (Photo courtesy of Laura Konecne). 


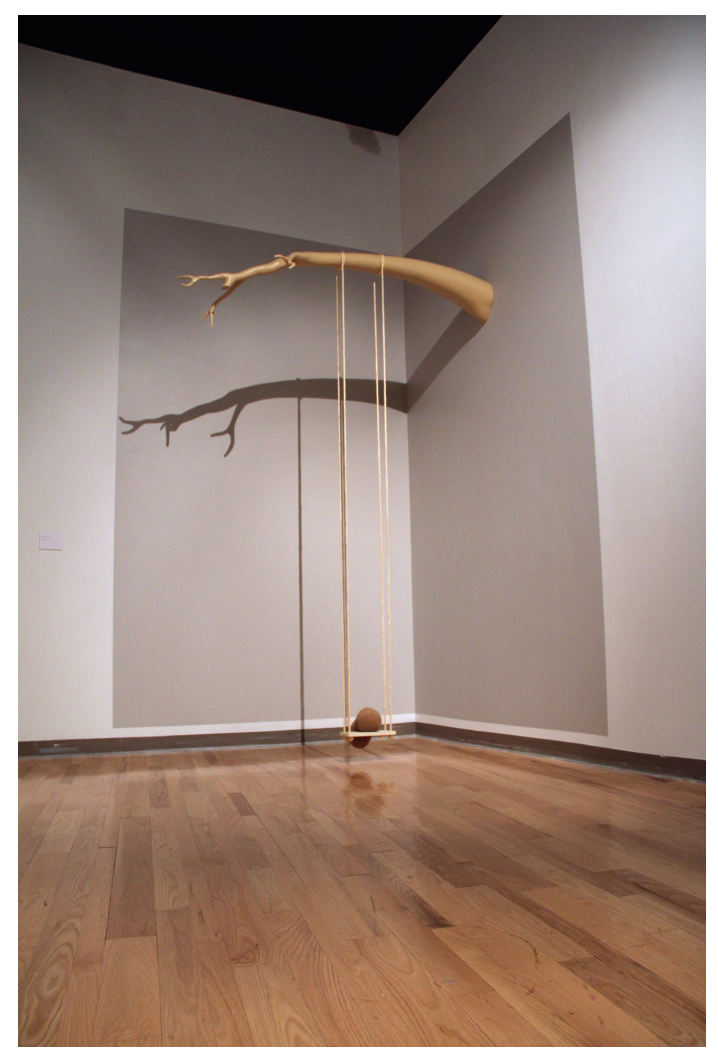

Fig. 17. Nate Ditzler, Fun without Friends (alternate view), 2016, ceramic, flocking, wood, dyed rope, paint. Dimensions variable. (Photo courtesy of Laura Konecne).

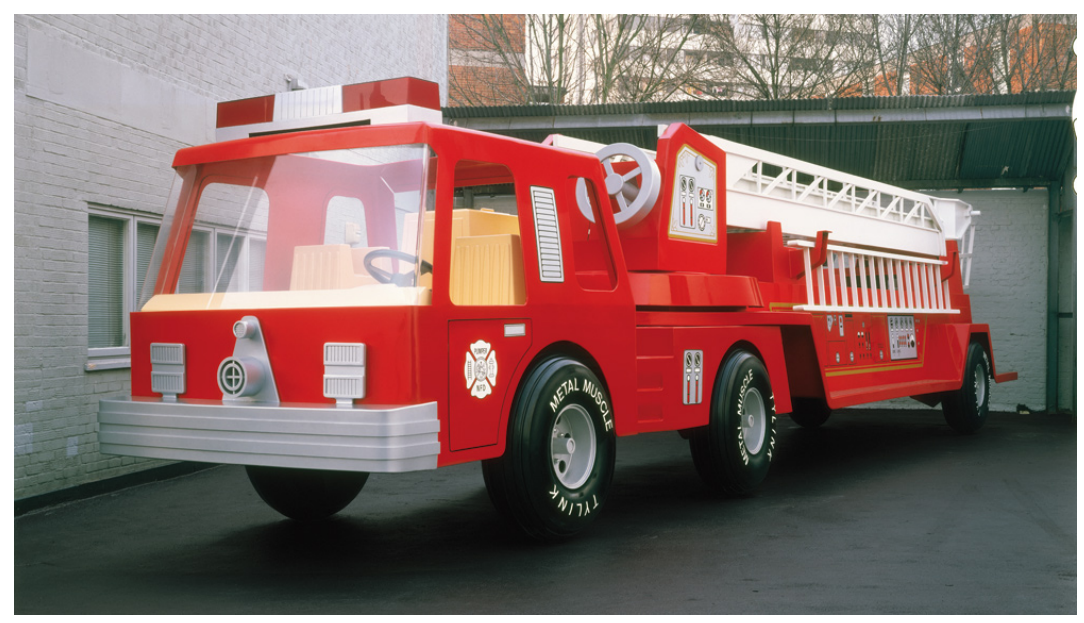

Fig. 18. Charles Ray, Firetruck, 1993, painted aluminium, fiberglass, and plexiglass. $365.8 \mathrm{x}$ $243.8 \times 1417.3 \mathrm{~cm}$. Reproduced from http://www.saatchigallery.com/aipe/charles_ray.htm (accessed April 1, 2016). 


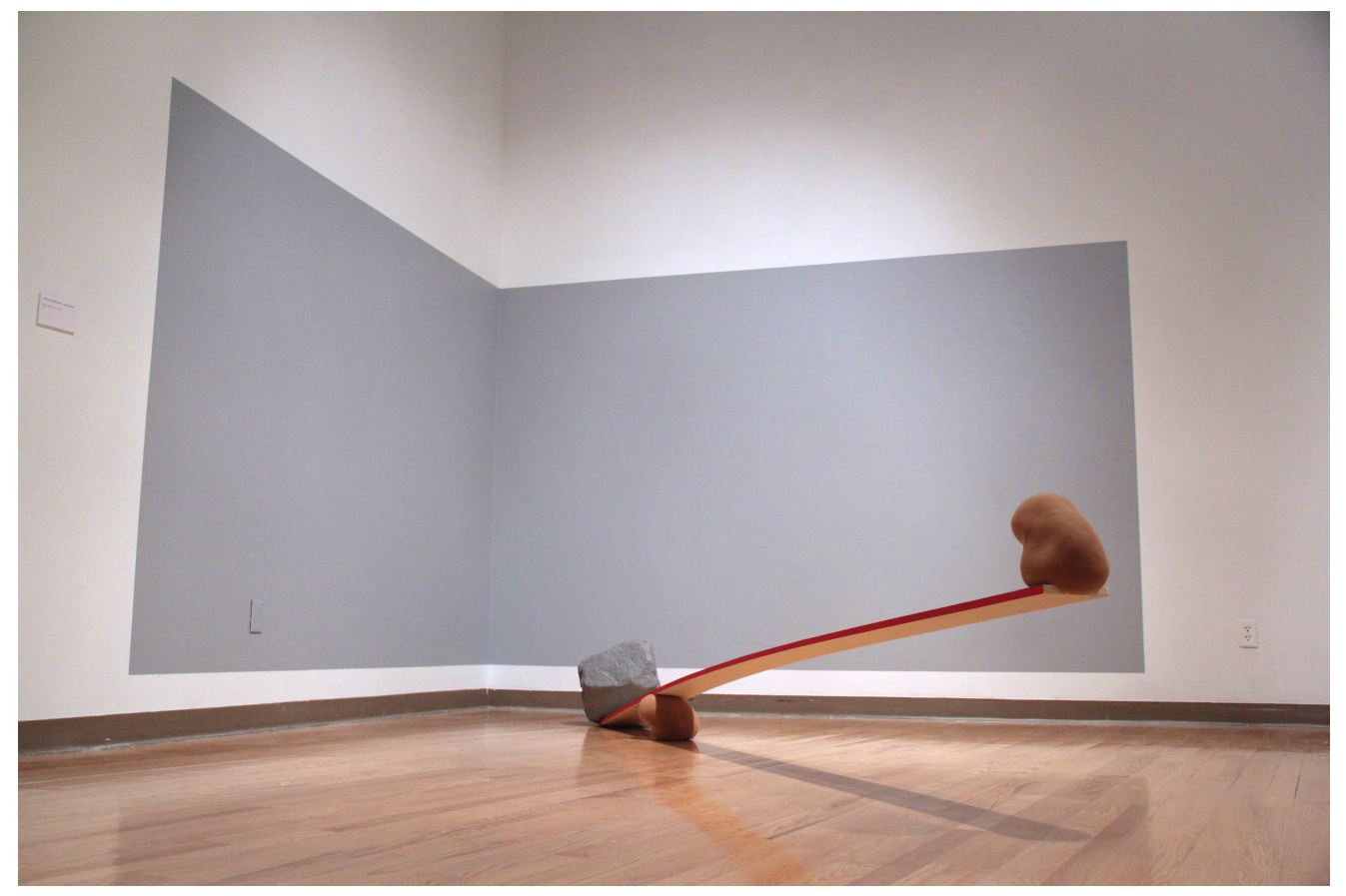

Fig. 19. Nate Ditzler, All Work and No Play Makes Us Younger Everyday, 2016, ceramic, flocking, wood, rock, paint. Dimensions variable. (Photo courtesy of Laura Konecne).

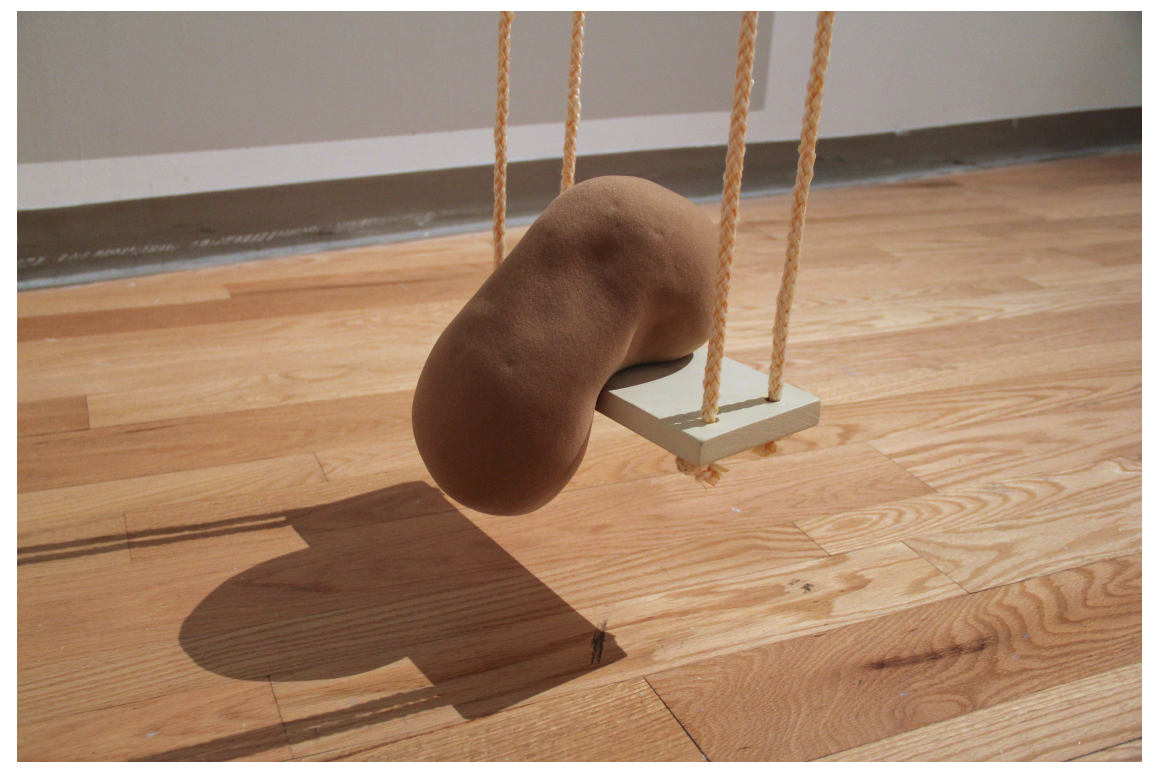

Fig. 20. Nate Ditzler, Fun without Friends (detail), 2016, ceramic, flocking, wood, dyed rope, paint. Dimensions variable. (Photo courtesy of Laura Konecne). 


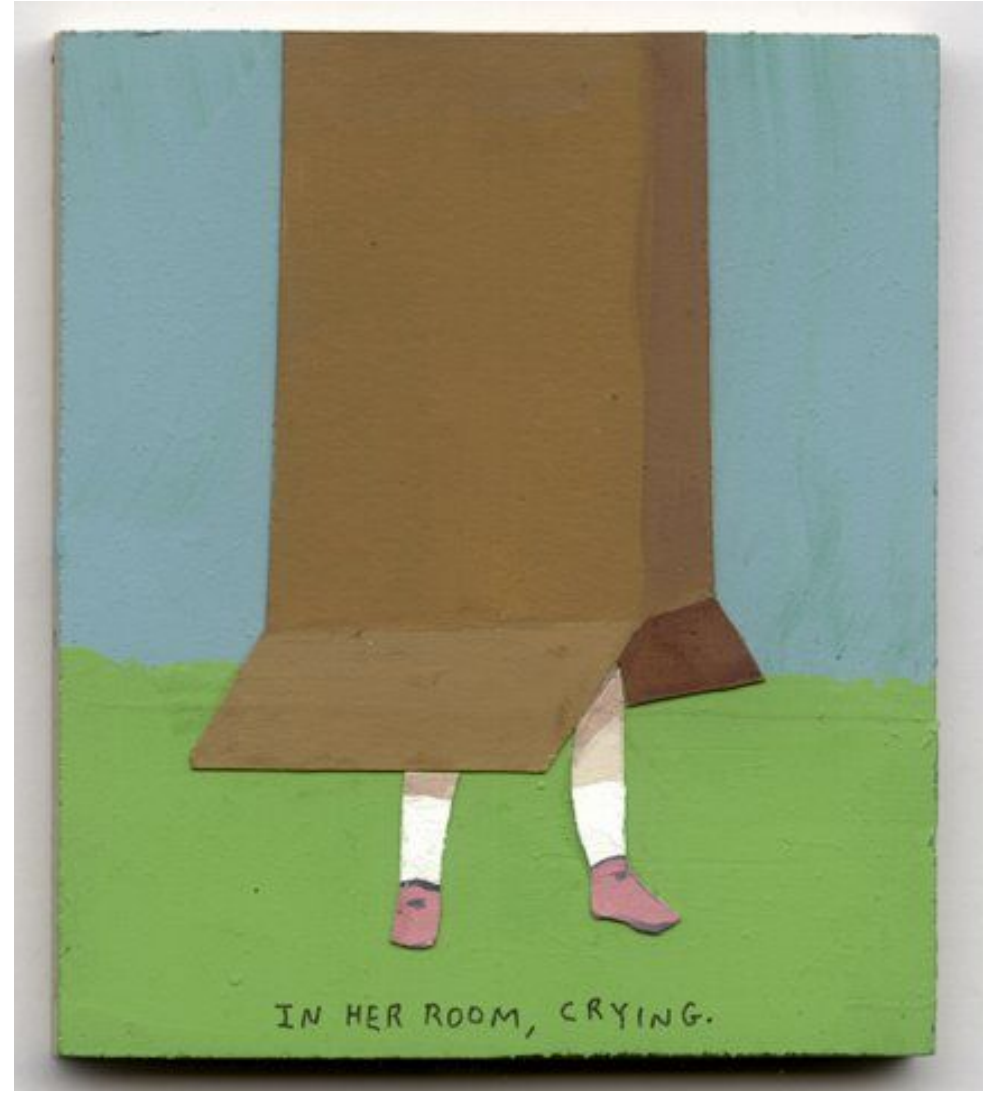

Fig. 21. The Royal Art Lodge, In Her Room, Crying, n.d. paint, paper. Reproduced from http://www.royalartlodge.com/children\%20one (accessed April 1, 2016). 


\section{Sunday, May 4 th}

I've decided to use the wheel, but only at night, when they're sleeping. Ill scratch and crawl and rattle the cage, just to annoy them, to show them I will not do tricks-that if I do anything, it is for $m e$, not for them.

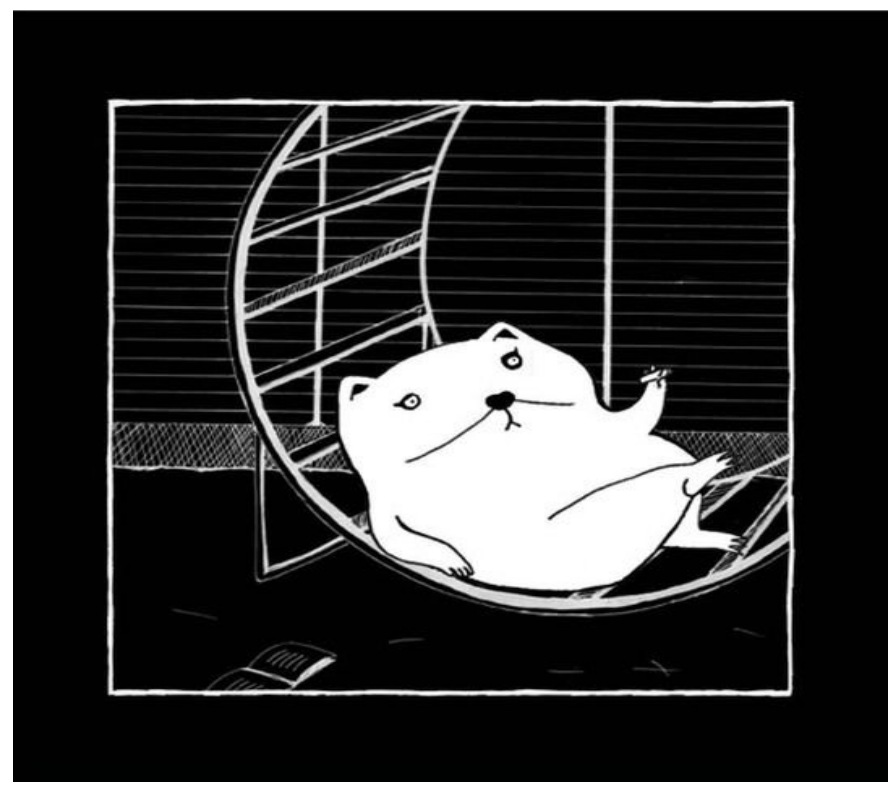

Fig. 22. Miriam and Ezra Elia, The Diary of Edward the Hamster 1990-1990, (New York: Blue Rider Press, 2013): 2. Reproduced from Google Books. 


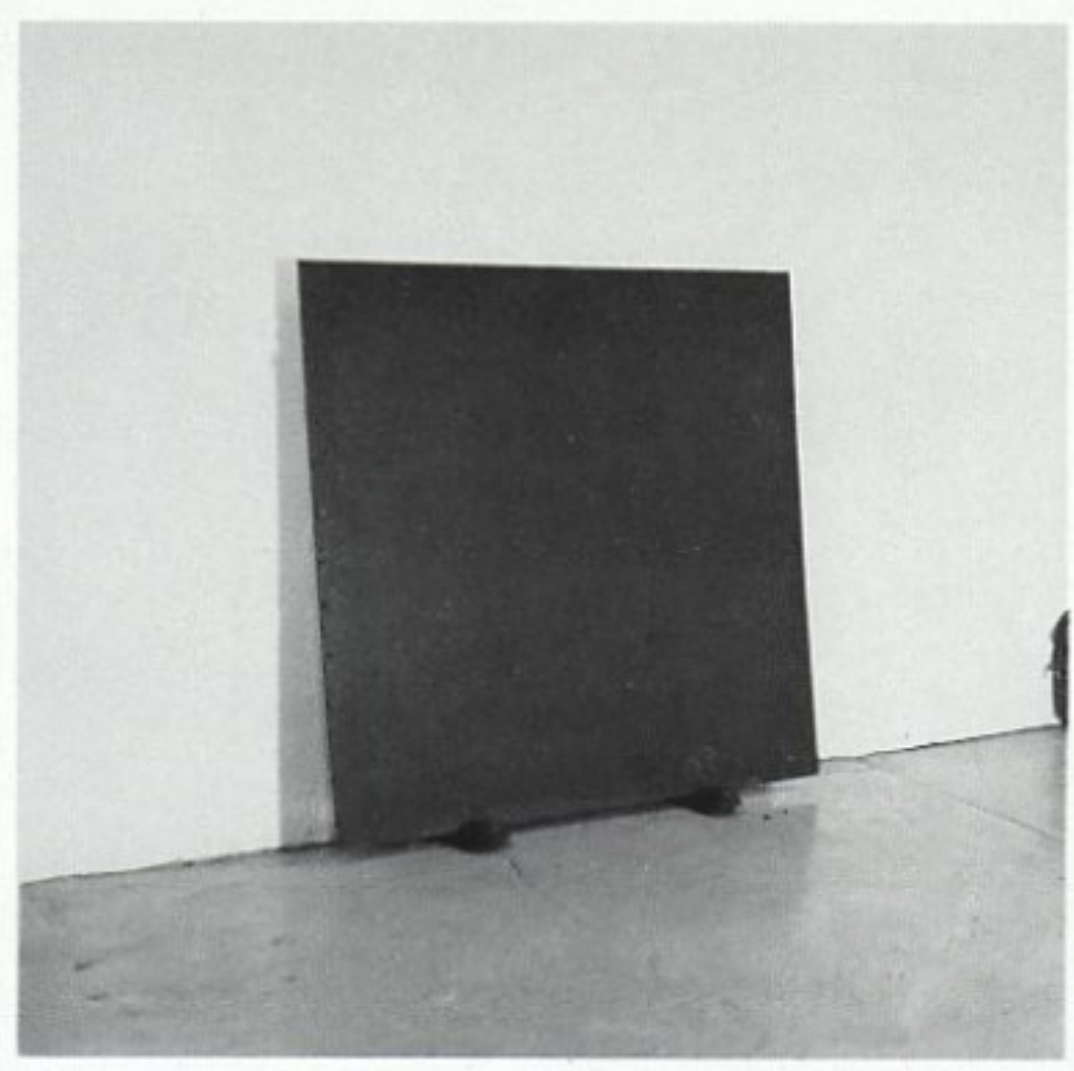

TO HIDE HIS DPORMTT HE MORB SPBCTAL CLOTHIVG

Fig. 23. William Wegman, To Hide His Deformity He Wore Special Clothing, 1971, photograph. Reproduced from https://littlefishchen.wordpress.com/2012/10/ (accessed April 1, 2016). 


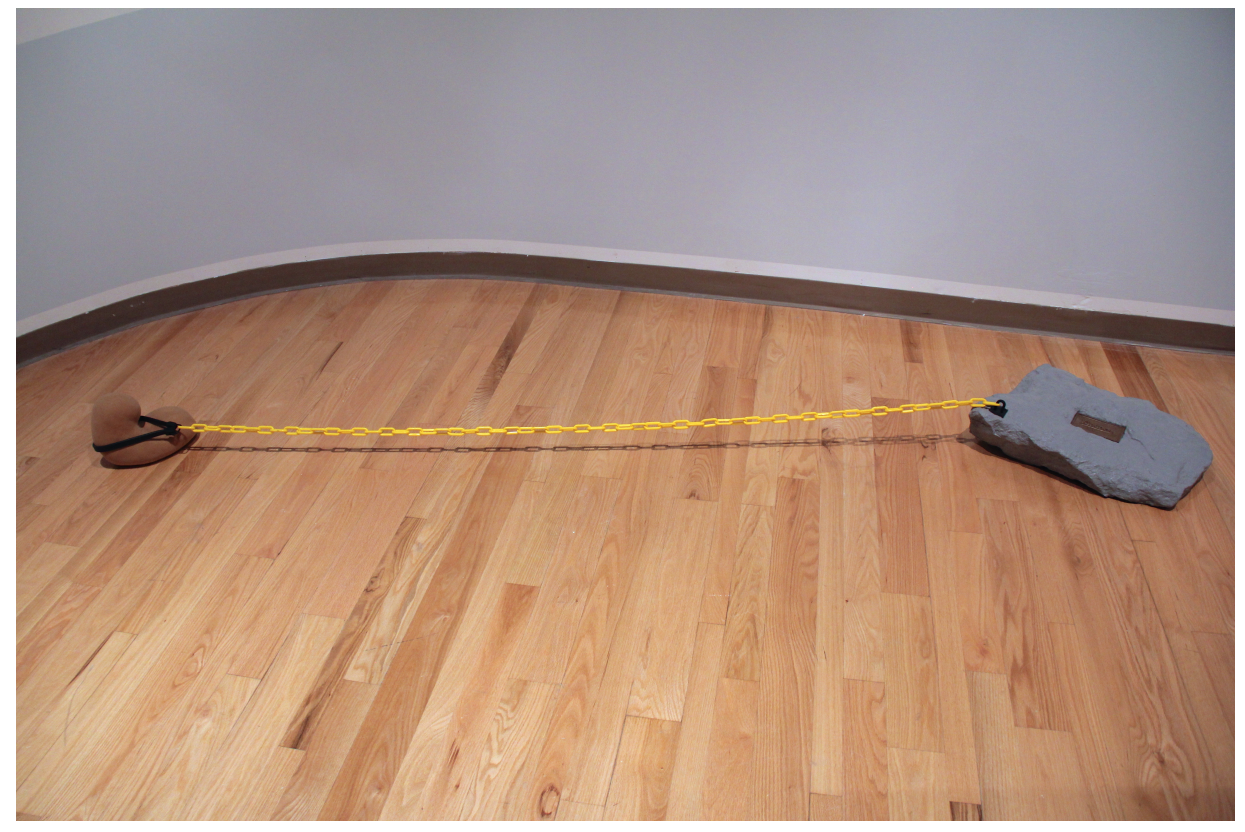

Fig. 24. Nate Ditzler, It's That Easy, 2016, ceramic, flocking, rubber band, plastic chain, rock, steel, cast resin with bronze powder, paint. Dimensions variable. (Photo courtesy of Laura Konecne).

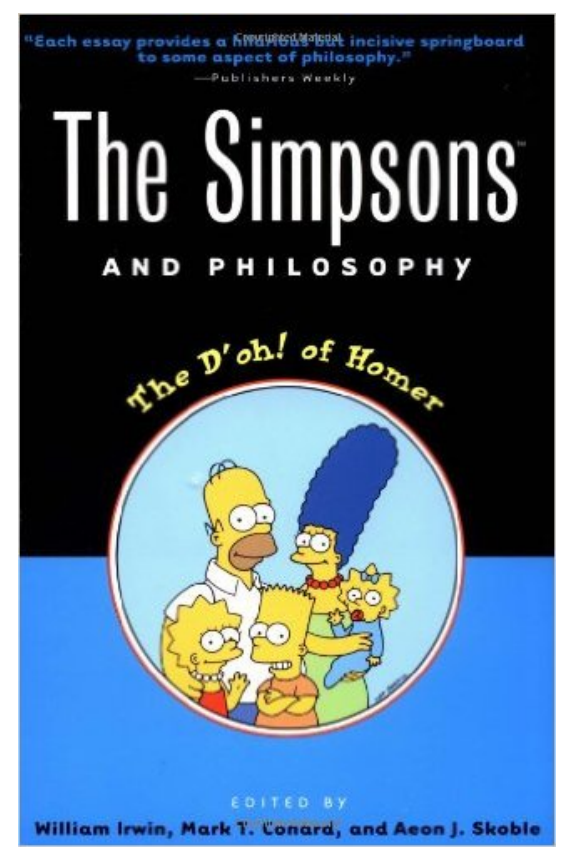

Fig. 25. Joan Sommers Design, The Simpsons and Philosophy: The D'oh of Homer, cover illustration, 2001. Reproduced from Google Books (accessed April 1, 2016). 


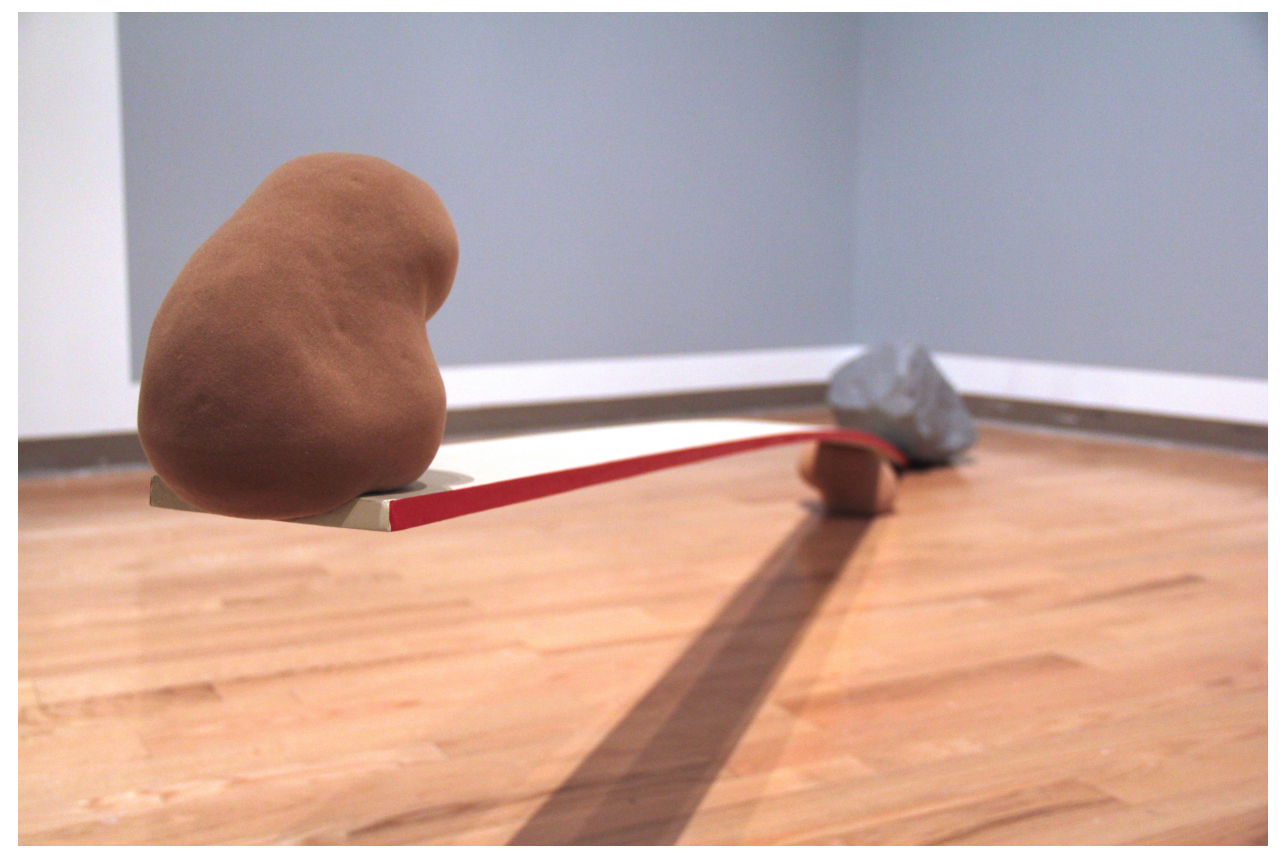

Fig. 26. Nate Ditzler, All Work and No Play Makes Us Younger Everyday (alternate view), 2016, ceramic, flocking, wood, rock, paint. Dimensions variable. (Photo courtesy of Laura Konecne).

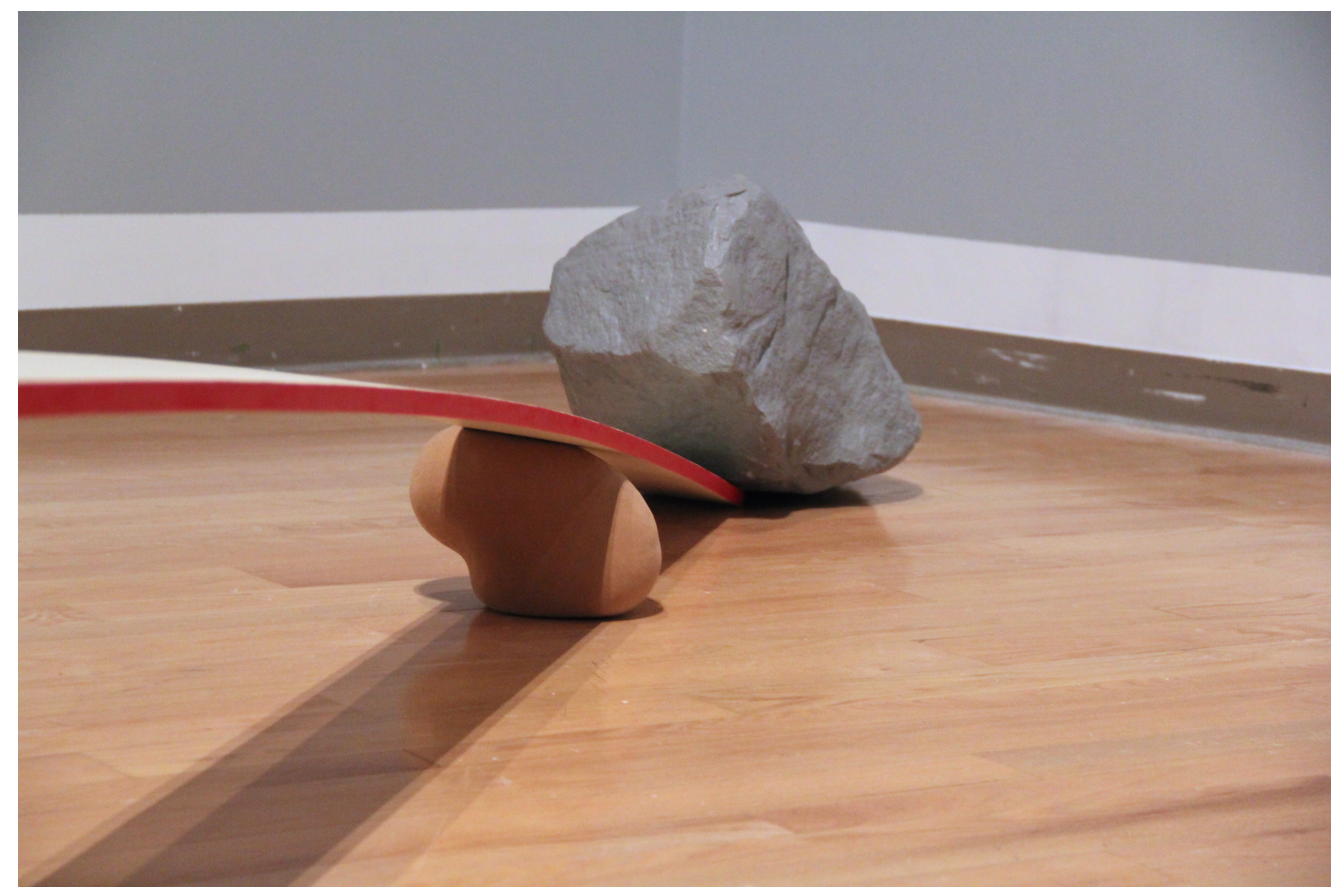

Fig. 27. Nate Ditzler, All Work and No Play Makes Us Younger Everyday (detail), 2016, ceramic, flocking, wood, rock, paint. Dimensions variable. (Photo courtesy of Laura Konecne). 


\section{Bibliography}

Art Journal for BA Art, Chelsea Art College, University of Arts London, "Talking to the Listening Tree," accessed April 6, 2016.

https://talkingtothelisteningtree.wordpress.com/2011/11/01/minimal_art/

Barber, Michael D., and Jochen Dreher, eds. The Interrelation of Phenomenology, Social Sciences and the Arts. (New York: Springer International Publishing, 2014).

Bartorelli, Guido, The Royal Art Lodge 13 de Junio al 28 De Septiembre de 2008, Burgos, Spain: Caja De Burgos, 2008.

Bronson, Eric. "Why Maggie Matters: Sounds of Silence, East and West." In The Simpsons and Philosophy: The D'oh! of Homer, edited by William Irwin. Chicago: Open Court, 2001.

Harris, Daniel. Cute, Quaint, Hungry and Romantic: The Aesthetics of Consumerism. New York: Basic Books, 2000.

Heiser, Jorg, All of a Sudden: Things That Matter In Contemporary Art, New York: Sternberg Press, 2008.

Higgie, Jennifer. The Artist's Joke. London: White Chapel, 2007.

Johnstone, Stephen, ed. The Everyday: Documents of Contemporary Art. Cambridge MA: The MIT Press, 2008.

Klein, Sheri. Art and Laughter. London: I.B. Tauris \& Co, 2007.

Lehner, Adam. The Royal Art Lodge: Ask the Dust; Dictionary of Received Ideas, New York: The Drawing Center, 2003.

Parry, Joseph D. Art and Phenomenology. New York: Routledge, 2011.

Pincus-Witten, Robert, PostMinimalism. New York: Out of London Press, 1977).

Preece, Robert, "Human Echo: A Conversation With Tony Matelli." In Sculpture 33, no. 1 January/February 2014. accessed March 25, 2016.

http://www.sculpture.org/documents/scmag14/janfeb_14/fullfeature-tony-matelli.shtml.

Ray, Charles, and Paul Schimmel. Charles Ray. Los Angeles: Museum of Contemporary, 1998.

Tomkins, Calvin. Marcel Duchamp: The Afternoon Interviews. Brooklyn, NY: Badlands Unlimited, 2013.

Wegman, William, and Martin Kunz. William Wegman: Paintings, Drawings, Photographs, Videotapes. New York: Abrams, 1990. 
Whitney, Kathleen, "Beth Cavener: Subliminal," In Ceramics Monthly 63, no. 9 November 2015. accessed April 1, 2016. http://ceramicartsdaily.org/ceramics-monthly/article/beth-cavenersubliminal/. 


\section{Nate Ditzler}

Address: 466 Dille St. apt 20, Morgantown, WV 26505

Telephone: (808) 222-6165

Email: nate.ditzler@gmail.com

nateditzler.com

\section{Education}

2016 Master of Fine Arts, West Virginia University, West Virginia

2012 Bachelor of Fine Arts, University of Hawaii at Manoa

2008 Bachelor of Arts, Cultural Anthropology University of Hawaii at Manoa

2006 Associate of Arts, University of Hawaii Windward Community College, Hawaii

\section{Professional Experience}

2016 Gallery Assistant, Mesaros Galleries, West Virginia University

2013-2016 Instructor of Record, West Virginia University, 2-D Foundations, Ceramics for Non-Majors, Graduate Teaching Assistantship: studio maintenance, materials inventory, fabrication of studio necessities

2012-2013 Teaching Assistant, University of Hawaii at Manoa, Ceramics Department, Honolulu, Hi

2011-2005 Teaching Assistant \& Lab Technician: Kiln firing, making studio clay, glaze making and calculations, facility maintenance, Windward Community College, Kaneohe, HI,

\section{Workshops / Lectures}

2013 “Nate Ditzler: Artist Presentation”, The Pottery Workshop: Sculpture Factory, Jingdezhen, Jiangxi Provence, China

2012 Pecha kucha, Bachelor of Fine Arts Capstone, University of Hawaii at Manoa, Honolulu, HI 
2011 "Nate Ditzler: Artist Presentation", Jingdezhen Ceramic Institute - West Virginia University International Studio, Jingdezhen, China

2011 Xian Jiaotong University, Xian, Shaanxi Provence, China

\section{Awards and Achievements}

2015 Shelton Gorelick Scolarship: Penland School of Crafts (full scholarship), Juror's Choice, Juried Student Exhibition, West Virginia University

2014 Pat Bibbee GPS Student Travel Award for Inter-Media studies in Chile, Pat Bibbee GPS Student Travel Award for Art \& Environment studies in Hawaii, Faculty-Student Mentored Graduate Research Award 2nd Place, Juror's Choice, Juried Student Exhibition, West Virginia University

2013-2016 Full Academic Scholarship, West Virginia University, Master of Fine Arts, Pat Bibbee GPS Student Travel Award for Ceramic Studies in Jingdezhen, China

2013 The Honolulu Japanese Chamber of Commerce: Commitment to Excellence, Recognition Award, (Purchase by Hawaii State Foundation for Culture and the Arts: Art in Public Places Program)

2012 The Mayor's Office of Culture and the Arts: Art Acquisitions (Purchased for Art in Public Places Program, Honolulu, HI Stella O. Lee Scholarship, Aha Hana Lima, Hawaii Craftsmen, Honolulu, HI

2011 The Luce Foundation Undergraduate Scholarship for study at Jingdezhen Ceramic Institute - West Virginia University International Studios

2011 Stella O. Lee Scholarship, Aha Hana Lima, Hawaii Craftsmen, Honolulu, HI

2005 Chancellors Award, Hawaii Community College Statewide Juried Exhibition, Windward Community College, Paliku Gallery, HI

\section{Solo Exhibition}

2016 A Case of the Mundanes: Master of Fine Arts Thesis Exhibition, West Virginia University

2014 The Waikiki Parc Features Nate Ditzler Solo, Waikiki Parc Hotel, Honolulu, HI 


\section{Juried Exhibitions}

2014-2015 Juried Student Exhibition, West Virginia University

2013 The Honolulu Japanese Chamber of Commerce: Commitment to Excellence, Honolulu Museum of Art, Honolulu HI

$2012 \quad 45^{\text {th }}$ Annual Hawaii Craftsman Annual Statewide Juried Exhibition, Honolulu Museum of Art, Honolulu, HI

2011 Ceramic Art Exhibition, With Clay, With Friendship, With World, Online Exhibition, Seoul, Korea

2010 Ceramic Art Exhibition, With Clay, With Friendship, With World, Online Exhibition, Seoul, Korea, $43^{\text {rd }}$ Hawaii Craftsman Annual Statewide Juried Exhibition, Honolulu Museum of Art, Honolulu, HI, Raku Ho'olaulea Annual Juried Exhibition, The Arts At Marks Garage, Honolulu, HI

$200942^{\text {nd }}$ Annual Hawaii Craftsman Annual Statewide Juried Exhibition, Honolulu Museum of Art, Honolulu, HI, Raku Ho'olaulea Annual Juried Exhibition, The Arts At Marks Garage, Honolulu, HI

$200740^{\text {th }}$ Annual Hawaii Craftsman Annual Statewide Juried Exhibition, Honolulu Museum of Art, Honolulu, HI, Raku Ho'olaulea Annual Juried Exhibition, The Arts At Marks Garage, Honolulu, HI

2006 Hawaii Statewide Community College Juried Exhibition, Windward Community College, Paliku Gallery, Kaneohe, HI

\section{Invitational Exhibitions}

2013-2016 Confluence, Artist Image Resource, Pittsburgh, PA

2013 Artists Without Borders, The Pottery Workshop, Jingdezhen, Jiangxi Provence China

2012 Render: Bachelor of Fine Arts Exhibition, University of Hawaii Art Gallery, Art Building, Manoa, HI

2011 Hangzhou Ceramic Exposition, Hangzhou, Jiangxi Provence, China, Jingdezhen Comprehensive College Exhibition, Jingdezhen, Jiangxi Provence, China, Jingdezhen Ceramic Institute International Student Exhibition, Jingdezhen, Jiangxi Provence, China, Claymates 3, The Gallery at Ward Center, Honolulu, HI, Bridge: A Ceramic Exhibition, The Arts At Marks Garage, Honolulu, HI, East West Ceramics Collaboration V (Assistant Exhibition), Commons Gallery, University of Hawaii at Manoa, HI 


\section{Works Published}

2011 Badao Art, China Hangzhou Cultural and Creative Industries Exposition Catalog

\section{Public Collections}

2013 The Hawaii State Foundation for Culture and the Arts: Art in Public Places Program, Honolulu, HI.

2012 The Mayor's Office of Culture and the Arts: Art in Public Places Program, Honolulu, HI

2011 Guan Ying Ge Buddhist Temple, Jingdezhen, Jiangxi Provence, China (Gift) 